\title{
Update in the methodology of the chronic stress paradigm: internal control matters
}

\author{
Tatyana Strekalova ${ }^{1,2^{*}}$, Yvonne Couch ${ }^{3}$, Natalia Kholod ${ }^{1,4}$, Marco Boyks $^{1}$, Dmitry Malin 5 , Pierre Leprince ${ }^{6}$ and \\ Harry MW Steinbusch ${ }^{1}$
}

\begin{abstract}
To date, the reliability of induction of a depressive-like state using chronic stress models is confronted by many methodological limitations. We believe that the modifications to the stress paradigm in mice proposed herein allow some of these limitations to be overcome. Here, we discuss a variant of the standard stress paradigm, which results in anhedonia. This anhedonic state was defined by a decrease in sucrose preference that was not exhibited by all animals. As such, we propose the use of non-anhedonic, stressed mice as an internal control in experimental mouse models of depression. The application of an internal control for the effects of stress, along with optimized behavioural testing, can enable the analysis of biological correlates of stress-induced anhedonia versus the consequences of stress alone in a chronic-stress depression model. This is illustrated, for instance, by distinct physiological and molecular profiles in anhedonic and non-anhedonic groups subjected to stress. These results argue for the use of a subgroup of individuals who are negative for the induction of a depressive phenotype during experimental paradigms of depression as an internal control, for more refined modeling of this disorder in animals.
\end{abstract}

Keywords: animal model of depression chronic stress, sucrose test, anhedonia, antidepressant treatment, gene expression profiling, neuroinflammation, mouse

\section{Introduction}

Depression is projected to become the second most common cause of disability worldwide by 2015. Depression as a major health issue is illustrated by its death-toll, which currently claims more lives per year than road-traffic accidents [1-4]. At the same time, there is an obvious need for an improvement in the treatment of depression, as up to $45 \%$ of depressed patients do not show improved mood after advanced therapy and 15\% of patients do not respond to any antidepressant therapies [5]. The Diagnostic and Statistical Manual, Fourth Edition (DSM-IV) defines depression by the presence of at least one of two core symptoms: anhedonia; a decreased ability to experience pleasures, and depressive mood; lasting minimally 2 weeks $[6,7]$. Since anhedonia, on the one hand, is a cardinal phenomenon of depressive disorders, and on the other, can be evoked in rodents, the hedonic deficit

\footnotetext{
* Correspondence: t.strekalova@maastrichtuniversity.nl

'Department of Neuroscience, Faculty of Health, Medicine and Life Sciences, Maastricht University, Maastricht, Netherlands

Full list of author information is available at the end of the article
}

might be considered as a primary feature to be addressed in pre-clinical models of depression. Coping and cognitive deficits, low exploratory motivation, circadian and sleep disturbances, aggressive and anxiety traits, decreased sexual and increased submissive behaviour, social avoidance, deterioration of the coat state and other changes, which can be evoked in animals, with some considerations [8] are regarded as parallels of subsidiary depressive symptoms $[9,10]$.

The aim of this review is to analyze the major methodological drawbacks in mouse models of depression with a focus on its principal feature, anhedonia, in a chronic stress paradigm, and to share with the reader several procedural modifications resulting from our own experiences with a chronic stress model in C57BL/6N mice. We believe that the changes to methodology proposed here provide important advances in modelling the neurobiological basis of depression in rodents and that their implication can help develop more effective therapeutic strategies.
C Biomed Central

(c) 2011 Strekalova et al; licensee BioMed Central Ltd. This is an Open Access article distributed under the terms of the Creative Commons Attribution License (http://creativecommons.org/licenses/by/2.0), which permits unrestricted use, distribution, and reproduction in any medium, provided the original work is properly cited. 


\section{Challenges in modelling depression and anhedonia using chronic stress paradigms}

The chronic stress paradigm is considered to have a greater aetiological relevance and face validity in mimicking depression than other animal models, and therefore has become one of the most broadly used preclinical paradigms of this disorder [11-14]. The first experiments using this model were undertaken by Katz and colleagues in rats, and involved rotating stressors applied over 21-days [15]. These procedures were later modified by Willner resulting in higher length of experiment and lower severity of stressor [16]. These experiments resulted in a decreased preference for, and intake of palatable solutions such as sucrose or saccharine. This was defined as stress-induced anhedonia. This anhedonic state was accompanied by an increase in the thresholds required for intracranial self-stimulation and was reversed by anti-depressants, but not by neuroleptics or anxiolytics $[13,17]$. By now, a number of variants of chronic stress procedures had been proposed in both rats and mice and had been shown to evoke, in addition to anhedonia, the subsidiary depressive-like features mentioned above [18-31].

Regrettably, a number of studies revealed inconsistencies in the induction of hedonic deficit in chronic stress models in both rats and mice [32-35]. For example, in one study, Wistar and PVG hooded rats were subjected to chronic mild stress; stressed animals of both lines showed "unreliable" decreases in sucrose intake, which were "inconsistent" over time. None of stressed animals showed a decrease in the intracranial self-stimulation, evaluated by $50 \%$ of maximal response rate in the rate/frequency function [36]. Problems with reproducibility could also be due partly to the limited accuracy of the sucrose test, which, in its current state, does not have sufficient resolution to discriminate between anhedonic and non-anhedonic individuals within a stressed population [37-39]. In addition, some of multi-disciplinary studies, using anhedonic chronic stress models of depression, have resulted in abstruse and contradictory outcomes, and failed to define a consistent molecular, neuroanatomical and physiological phenotype in either rats or mice. Data on their locomotion, anxiety, exploration, and other behaviours often demonstrated paradoxical and conflicting behavioural changes; many of them showed discrepancies between the behavioural phenotype of chronically stressed animals and human symptoms of depression. Together, controversies with reproducibility of stress-induced anhedonia, defined by sucrose preference data and identification of biological correlates of depression greatly limit the value of this method to model pre-clinical depression [40].

Apart from methodological problems, application of the chronic stress approach has encountered some conceptual drawbacks. The most obvious is that in previously proposed models, all effects observed in groups of chronically stressed animals with signs of a decreased sensitivity to reward, are attributed to an hedonic deficit. It is important to note that stress alone can evoke a number of physiological alterations, which are not associated with a depressive-like behavior and anhedonia. With the originally proposed models and their analogues it was not possible to correlate findings obtained in chronically stressed animals with anhedonia, thus, specific biological correlates of hedonic deficit could not be addressed.

Studies with our new model of stress-induced anhedonia suggest that unresolved methodological difficulties in measuring behaviour in chronically stressed animals may be the origin of the above problems. Here, we present data obtained across several experiments, which reveal the major sources of behavioural artifacts in chronic stress mouse models of depression. These data enable us to propose several changes to the accepted methodology which are validated by both behavioural and molecular correlates of anhedonia.

\section{Anhedonia is exhibited by a subgroup of animals in chronic stress paradigms}

Numerous findings show a remarkable inter-individual variability in animals' responses to stress [9,13,41-43]. Using a principle of the isolation of responders and nonresponders, we have established a mouse model of stressinduced anhedonia with an internal control for the effects of stress alone [44]. A four week chronic stress paradigm, comprised of exposing male 3-months-old C57/BL6N mice to tail suspension and restraint stress in different procedural variants resulted in a decrease of preference to $1 \%$ sucrose solution by $\leq 65 \%$ in $50-70 \%$ of animals [[44-49]; Figure 1]. It was shown that sucrose preference is similar in control, non-anhedonic and anhedonic mice before the onset of stress. At the end of the stress induction period sucrose preference and intake markedly decrease and are replaced by an increase in water consumption.

Recent studies in chronically stressed mice and rats have shown similar partial depressive-like outcomes ([21-25]; see Table 1). Resilience or susceptibility to stress-induced anhedonia and/or other physiological parallels of depressive-like state in newly developed models was found to correlate with distinct regulation of mesolimbic dopamine circuits, excitability of dopamine neurons of ventral tegmental area [21,50], activity of the medial prefrontal cortex, nucleus accumbens and amygdala $[21,51]$, differential expression of neuropeptide $Y$, transcription and factors markers, immediate early genes, a dysfunction in the GABAergic system and AMPAmediated transmission [21,23,51-57], as well as changes in learning capacities including working memory $[56,57]$ and hippocampal neurogenesis [58]. 


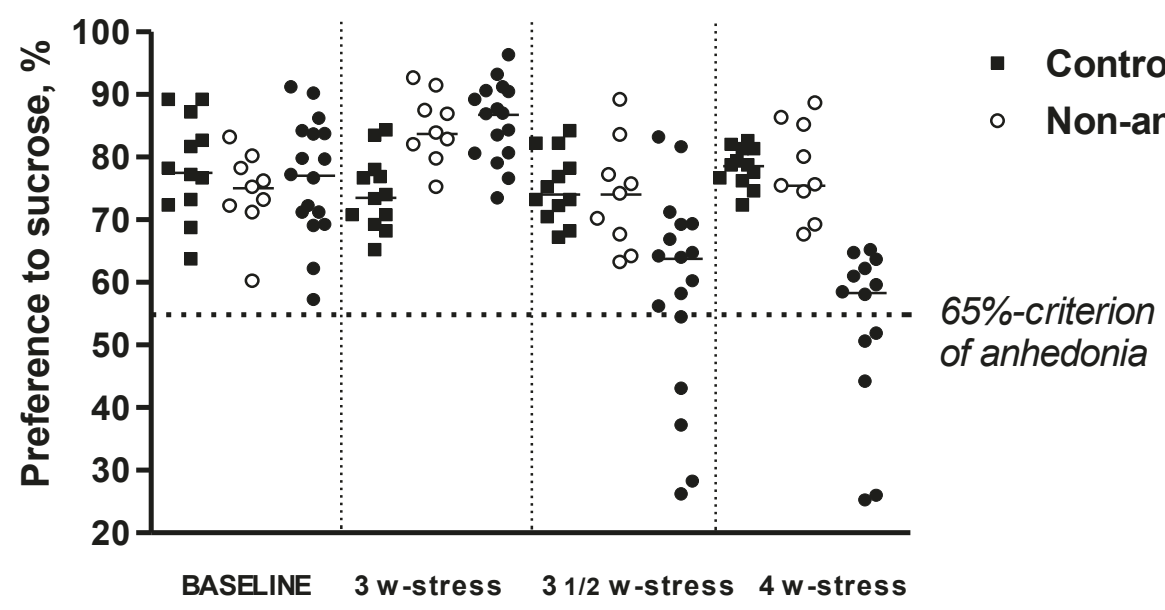

Figure 1 Chronic stress results in decreased sucrose preference in a subgroup of mice. After initial increase in sucrose preference on the 3rd week of stress, by the termination of a 4-week stress, a cohort of mice display a prominent decrease in sucrose preference. Mice subjected to chronic stress were split into anhedonic and non-anhedonic subgroups according to the criterion of $65 \%$ preference for sucrose solution (see the text), Reproduction of this material is permitted by Macmillan Publishers Ltd.

The inter-individual variability in susceptibility or resilience to stress-induced decreases in sucrose preference observed in these, and our, paradigms suggest that this phenomenon is typical, even for inbred lines of animals [21,56,59-63]. A variety of potential mechanisms may underlie this phenomenon: 1) pre-natal and early environmental factors [64] epigenetic mechanisms consisting in DNA and chromatin modifications, histone acetylation and methylation $[65,66]$ and switches and error-prone DNA replicates [67]; 3) large-scale organization of gene expression levels and multigenic trait mechanisms $[68,69]$, 7) posttranslational regulation of proteins [70]. Generally, preservation, even in genetically homogenious lines of animals, of inter-individual variability of physiological parameters allows one to develop hypotheses regarding its importance as a biological factor of adaptation and survival, especially relevant in a stressful environment, which may be mediated by specific biological mechanisms.

\section{Physiological features of stress and stress-induced} anhedonia in mice

Original protocols using C57BL/6N mice for studying emotionality, locomotion, exploration, cognition and other functions $[38,71,72]$ were modified in order to preclude behavioural artifacts in testing chronically stressed mice (see below). So-called "mild" testing conditions applied with these modifications, were aimed at the reduction of stress in animals during their testing and therefore preventing the occurrence of stress-induced hyperlocomotion. Behavioural features of anhedonic and non-anhedonic mice are summarized in the Table 2. In contrast to non-anhedonic animals, anhedonic mice revealed increased floating during the forced-swim test and immobilization behaviour in the tail suspension test, reduced exploration of a novel environment and object, impaired hippocampal-dependent performance in the step-down passive avoidance, Y-maze and contextual fear conditioning tasks, and disrupted burrowing behaviour in the food displacement test. A development of the latter deficit, as well as of behavioural despair and disruption of contextual learning were precluded by chronic antidepressant treatment in our model [[46], Tokarski et al.: Impaired hippocampal plasticity in mice with hedonic deficit, induced by chronic stress, unpublished)]. The above listed changes in behaviour are considered as analogues of those seen in patients, diminished interest in

Table 1 Partial depressive-like outcomes in chronic stress models of depression

\begin{tabular}{lllll}
\hline Stress & Laboratory strain & Measure of a depressive-like state & Susceptibility rate & Reference \\
\hline 6-week CMS & Wistar rats & Low sucrose preference & $51.5 \%$ & {$[25]$} \\
\hline 5-week social stress & CD1 mice & Increase of CORT, Low sucrose preference & $20 \%$ & \\
\hline 7-week CMS & Wistar rats & Low sucrose intake & $50-70 \%$ & {$[24,57]$} \\
\hline 10-day social defeat & C57BL/6J & Social avoidance, Low sucrose preference & $50-70 \%$ & {$[23,54-56]$} \\
\hline 7-week unpredictable CMS & Eleven common mouse strains & Coat deterioration, Low sucrose preference & Vary in different strains & {$[22,41,60]$}
\end{tabular}

Recent studies identified susceptible and resilient subpopulations of chronically stressed mice defined by anhedonia occurrence in a sucrose test, deterioration of a coat state, or an increase in basal CORT levels. 
Table 2 Physiological correlates of stress and stress-induced anhedonia in our model

\begin{tabular}{|c|c|c|c|}
\hline Physiological variable & $\begin{array}{l}\text { Anhedonic } \\
\text { Changes vs. } \\
\text { control }\end{array}$ & $\begin{array}{l}\text { Non-anhedonic } \\
\text { Changes vs. control }\end{array}$ & Reference \\
\hline 1. Floating in forced swim test & Increased & Not changed & {$[38,44,45]$} \\
\hline $\begin{array}{l}\text { 2. Immobilization in } \\
\text { tailsuspension test }\end{array}$ & Increased & Not changed & {$[39,47]$} \\
\hline 3. Novelty exploration & Decreased & Not changed & {$[44]$} \\
\hline 4. Burrowing behaviour & Decreased & Increased & {$[38,39]$} \\
\hline $\begin{array}{l}\text { 5. Contextual memory in } \\
\text { passive avoidance }\end{array}$ & Decreased & Not changed & {$[38]$} \\
\hline 6. Contextual fear conditioning & Decreased & Not changed & $\begin{array}{l}\text { [Tokarski et al. Impaired hippocampal plasticity in mice with } \\
\text { hedonic deficit, induced by chronic stress (unpublished)] }\end{array}$ \\
\hline $\begin{array}{l}\text { 7. LTP in the CA1 area of the } \\
\text { hippocampus }\end{array}$ & Disrupted & Not changed & $\begin{array}{l}\text { [Tokarski et al. Impaired hippocampal plasticity in mice with } \\
\text { hedonic deficit, induced by chronic stress (unpublished)] }\end{array}$ \\
\hline 8. REM sleep & Increased & Not changed & {$[46,48]$} \\
\hline $\begin{array}{l}\text { 9. Home cage activity during } \\
\text { dark phase }\end{array}$ & Increased & Not changed & {$[47]$} \\
\hline $\begin{array}{l}\text { 10. Anxiety-like behavior in } 0 \text { - } \\
\text { maze and dark-light box }\end{array}$ & Increased & Increased & {$[38,44,108]$} \\
\hline $\begin{array}{l}\text { 11. Open field locomotion } \\
\text { under modest lighting }\end{array}$ & Increased & Increased & {$[38,44,108]$} \\
\hline 12. Aggressive behavior & Increased & Increased & [[95], unpublished data] \\
\hline 13. Auditory fear conditioning & Not changed & Not changed & $\begin{array}{l}\text { [Tokarski et al. Impaired hippocampal plasticity in mice with } \\
\text { hedonic deficit, induced by chronic stress (unpublished] }\end{array}$ \\
\hline 14. Body weight & Decreased & Decreased & {$[38,39,44-49]$} \\
\hline
\end{tabular}

Eight out of fourteen evaluated physiological variables had differential changes in anhedonic and non-anhedonic animals, as compared to control. Remaining parameters were either not altered in these groups, or were changed in the same direction, suggesting that not all physiological consequences of stress can be attributed to anhedonia in the employed model.

novelty, cognitive decline and impairment of declarative memory $[6,7]$. These symptoms were mimicked in preclinical studies, many of which revealed the curative effects of antidepressants[9,10,13].

As well as behavioural changes, we found specific physiological abnormalities in anhedonic animals; a lack of ex-vivo LTP induction capacity in the CA1 area of the hippocampus during high frequency stimulation protocols, elevated duration of REM sleep and home cage hyperlocomotion (Table 2). Chronic treatment with an SSRI precluded stress-induced disruption of LTP induction in hippocampal slices. This data correlates with human studies showing that impaired hippocampal function and synaptic plasticity are sensitive to antidepressant treatment $[73,74]$. The augmentation of REM sleep and disturbances in diurnal rhythms observed in clinical studies and animal models of depression are thought to be characteristic of clinical depression [3-7,18,20]. In particular, depressed patients exhibit a high percentage of REM sleep when compared to other neuropsychiatric disorders with shared pathophysiology.

At the same time, many changes in animals were found to occur in stressed animals irrespectively of the presence of hedonic deficit: hyperlocomotion observed in brightly illuminated open field, hypoactivity in the dark open field, increased scores of anxiety-like behaviour in the dark/light and elevated O-maze tests, high scores of aggressive behaviour and loss of body weight (Table 2). Increased scores of anxiety, aggressive behaviour, locomotor inhibition and behavioural invigoration are also well documented in humans and are thought to be the result of stressful experiences [3-7,28,31,75].

In the present model, stress-induced loss of body weight, high scores of anxiety and locomotor diturbances are comparable in anhedonic and non-anhedonic mice that might be regarded as an indication of similar impact of the stress in these animals. Data concerning anxiogeniclike changes in the $\mathrm{O}$-maze in C57BL/6J mice with and without social avoidance and anhedonia evoked by social defeat stress [21] are in line with our findings. In this study, no difference in body weight between two groups was observed at the time point of experiment, when signs of elevated depressive- and anxiety-like behaviour were revealed in stressed animals. The CD1 mice, either resilient or susceptible to chronic social stress, as measured by changes of basal CORT levels and sucrose preference, showed no alterations in body weight [57]. In studies on other mouse lines, a manifestation of stress-induced depressive-like features correlated with a loss of body mass $[13,23,41,60]$. This suggests that species-specific 
differences across different strains of laboratory mice may underlie a distinct relationship between anhedonia and body weight. In line with our results, both anhedonic and non-anhdonic Wistar rats in the chronic stress model were found to have similarly decreased body weight [25]. We believe that the absence of differences in body mass in our model between anhedonic and non-anhedonic mice may be caused by the 'ceiling effect' of stress on physical parameters in a specific strain. Similar values of body weight in subgroups of stressed mice can be an important factor, which prevents significant confounds in the behavioural comparison of anhedonic and non-anhedonic mice. Should body weight vary between these groups, their comparison in behavioural tests based, for example, on the measurement of liquid intake and foot shock application is likely to be compromised by distinct metabolic features and a response to an electrical stimulation.

The latest literature suggests a link between common inflammatory factors, loss of body weight and sickness behaviour - a state which is related to anhedonia. In the light of recent identification of inflammatory factors, which underlie both sickness behaviour and depression [76], it can be speculated that stress-induced decreases in body weight, in addition to classical mechanisms of hormonal secretion and sympathetic activation, might be mediated by activated inflammatory pathways involved in the pathogenesis of anhedonia. Of note, in our model stressed, anhedonic mice showed disrupted burrowing behaviour that we believe to be related to both lesions of the dorsal hippocampus and sickness behaviour $[38,39,77]$. While, in our studies, both susceptible and resilient animals showed a robust decrease in body weight, a potential contribution of inflammatory factors to this consequence of stress could be an interesting question to be addressed experimentally.

Interestingly, elevated anxiety was found in stressed animals irrespective of the occurrence of hedonic deficit, supporting the clinical view of the comorbidity of anxiety and depression, where core pathogenetic mechanisms are thought to be distinct $[78,79]$. These distinct mechanisms are used to separate anxiety from anhedonia in animal models of depression. Of importance, a stress-induced anhedonic state was found to be selectively associated with depressive-like features, which were not observed in stressed non-anhedonic animals. In contrast, pathological changes that are common for a broad spectrum of stressrelated disorders besides depression, e.g., behavioural invigoration, and high anxiety are shared between stressed mice with and without depressive-like features. The fact that anhedonic mice display depressive-like traits which are not detected in the non-anhedonic group speak in favour of the face validity of the employed model as a model of depression at the first instance, and argue for the adequacy of the latter group as a proper control for the effects of stress that are not associated with a depressivelike state. Several groups who have employed a similar approach have obtained comparable outcomes that further support our original findings concerning differential physiological profiles of animals resilient and susceptible to stress-induced depression (Table 3).

\section{Identification of molecular correlates of stress and stress- induced anhedonia}

Altered functional activity within the hippocampal formation is thought to be important hallmark of stress and a depressive-like state [80,81]. Utilizing the hippocampi of control versus stressed anhedonic and non-anhedonic mice, gene expression profiling has been performed using Illumina technology (IntegraGen, Evry, France) and the Ingenuity Pathway Analysis program (Ingenuity Systems, Redwood city, CA, USA). Anhedonic and non-anhedonic mice displayed substantial changes in clusters of genes

Table 3 Features of resilience and susceptibility to stressinduced depressive state in animal models

\begin{tabular}{|c|c|c|}
\hline Physiological variable & Susceptible & Resilient \\
\hline Sucrose intake/preference & $\begin{array}{l}\text { Decreased } \\
\text { [21-25] }\end{array}$ & $\begin{array}{c}\text { Not changed } \\
{[21-25]}\end{array}$ \\
\hline Behavioural despair & $\begin{array}{c}\text { Increased } \\
{[23,25]} \\
\text { Not changed } \\
{[21]}\end{array}$ & $\begin{array}{c}\text { Not changed } \\
{[21,23,25]}\end{array}$ \\
\hline Social avoidance & $\begin{array}{c}\text { Increased } \\
{[21,22]}\end{array}$ & $\begin{array}{c}\text { Not changed } \\
{[21,22]}\end{array}$ \\
\hline Novelty exploration & $\begin{array}{c}\text { Decreased } \\
{[21,22]} \\
\text { Increased [25] }\end{array}$ & $\begin{array}{c}\text { Not changed } \\
{[21,22]} \\
\text { Increased [25] }\end{array}$ \\
\hline Contextual memory & $\begin{array}{c}\text { Decreased [24] } \\
\text { Not changed } \\
{[23]}\end{array}$ & $\begin{array}{c}\text { Not changed } \\
{[23,24]}\end{array}$ \\
\hline Working memory & Decreased [24] & Not changed [24] \\
\hline $\begin{array}{l}\text { Coat state and self- } \\
\text { grooming }\end{array}$ & $\begin{array}{c}\text { Impaired } \\
{[22,24]}\end{array}$ & $\begin{array}{c}\text { Not changed } \\
{[22,24]}\end{array}$ \\
\hline Anxiety-like behavior & $\begin{array}{c}\text { Increased } \\
{[21,22,24]} \\
\text { Not changed } \\
{[25]}\end{array}$ & $\begin{array}{c}\text { Increased } \\
{[21,22,25]} \\
\text { Not changed [24] }\end{array}$ \\
\hline Body weight & $\begin{array}{c}\text { Decreased } \\
{[21,22,25]} \\
\text { Not changed } \\
{[21-24]}\end{array}$ & $\begin{array}{c}\text { Decreased } \\
{[21,22,25]} \\
\text { Not changed } \\
{[21-24]}\end{array}$ \\
\hline Social hyperthermia & Increased [21] & Not changed [21] \\
\hline Stress-induced polydipsia & $\begin{array}{c}\text { Increased } \\
{[21]}\end{array}$ & $\begin{array}{c}\text { Not changed } \\
{[21]}\end{array}$ \\
\hline Circadian amplitude & Dereased [21] & Not changed [21] \\
\hline $\begin{array}{l}\text { Conditioned place } \\
\text { preference }\end{array}$ & Increased [21] & Not changed [21] \\
\hline
\end{tabular}

Newly available models of depression which differentiate resilient and susceptible cohorts of animals enable a distinction of their physiological profiles. Original reports describing animal paradigms are quoted; in some cases dependently on the measure taken and the strain used the outcome varied within the same paradigm. 
involved in specific biological functions important to sustain various CNS processes (Table 4). While a detailed analysis of the likely outcomes of the affected functions on hippocampal physiology has not been performed, it is interesting to note that some of the observed changes in anhedonic mice are part of categories consisting of negative or inhibitory processes. These include such clusters of functions classified with the Ingenuity Pathway
Analysis program, as impaired psychological processes, coordination and memory, pre-pulse inhibition and long term and synaptic depression. Genes related to neurological disease and disorders, and to neurodegeneration are also affected. For the non-anhedonic mice, the functions with higher gene expression are important in such processes as biogenesis, formation, growth and development of cells, neurites and vesicles. Positive behaviour and

Table 4 Comparison of gene expression in anhedonic and resilient stressed mice versus non-stressed controls

\begin{tabular}{|c|c|c|c|c|c|c|c|}
\hline \multirow[t]{2}{*}{ Category } & \multirow[t]{2}{*}{ Function } & \multicolumn{2}{|c|}{ Anhedonic } & \multicolumn{3}{|c|}{ Resilient } & \multirow[b]{2}{*}{ p-value } \\
\hline & & $\begin{array}{l}\text { \# Genes } \\
\text { Up }\end{array}$ & $\begin{array}{l}\text { \# Genes } \\
\text { Down }\end{array}$ & p-value & $\begin{array}{l}\text { \# Genes } \\
\text { Up }\end{array}$ & $\begin{array}{l}\text { \# Genes } \\
\text { Down }\end{array}$ & \\
\hline \multirow{6}{*}{$\begin{array}{l}\text { Cellular Assembly and } \\
\text { Organization }\end{array}$} & transport of vesicles & & & N.S. & 41 & & $4.22 \mathrm{E}-07$ \\
\hline & $\begin{array}{l}\text { biogenesis of } \\
\text { cytoskeleton }\end{array}$ & & & N.S. & 35 & 3 & $5.41 \mathrm{E}-06$ \\
\hline & $\begin{array}{l}\text { morphogenesis of } \\
\text { neurites }\end{array}$ & & & N.S. & 33 & & $7.25 \mathrm{E}-06$ \\
\hline & formation of vesicles & & & N.S. & 25 & & 2.04E-05 \\
\hline & formation of filaments & 11 & 13 & 4.47E-05 & & & N.S. \\
\hline & formation of neurites & 4 & 8 & $8.47 \mathrm{E}-05$ & & & N.S. \\
\hline \multirow[t]{6}{*}{ Behavior } & cognition & 9 & 6 & $2.62 \mathrm{E}-03$ & 57 & 1 & 2.97E-06 \\
\hline & behavior & 30 & 16 & $1.29 \mathrm{E}-04$ & & & N.S. \\
\hline & learning & & & N.S. & 48 & 1 & 2.13E-05 \\
\hline & $\begin{array}{l}\text { psychological process of } \\
\text { mice }\end{array}$ & 23 & 10 & $2.49 \mathrm{E}-04$ & & & N.S. \\
\hline & memory & 10 & 5 & $3.01 \mathrm{E}-04$ & & & N.S. \\
\hline & $\begin{array}{l}\text { exploratory behavior of } \\
\text { mice }\end{array}$ & 6 & 1 & $1.80 \mathrm{E}-04$ & 14 & & 5.37E-04 \\
\hline \multirow[t]{2}{*}{ Cellular Movement } & movement of brain cells & & & N.S. & 30 & 1 & $3.40 \mathrm{E}-06$ \\
\hline & migration of brain cells & & & N.S. & 29 & 1 & 4.59E-06 \\
\hline \multirow{11}{*}{$\begin{array}{l}\text { Nervous System Development and } \\
\text { Function }\end{array}$} & development of neurites & 18 & 4 & $1.67 \mathrm{E}-05$ & 63 & & $6.50 \mathrm{E}-06$ \\
\hline & development of axons & 11 & 4 & $3.10 \mathrm{E}-05$ & 34 & & 1.35E-03 \\
\hline & long-term potentiation & 10 & 5 & $2.54 \mathrm{E}-03$ & 50 & 3 & 1.60E-05 \\
\hline & long term depression & 6 & 3 & $5.95 \mathrm{E}-04$ & & & N.S. \\
\hline & synaptic transmission & 13 & 6 & 2.77E-05 & 50 & & 1.29E-04 \\
\hline & $\begin{array}{l}\text { prepulse inhibition of } \\
\text { mice }\end{array}$ & 8 & 2 & $2.66 \mathrm{E}-06$ & & & N.S. \\
\hline & coordination of mice & 5 & 2 & $9.73 \mathrm{E}-05$ & & & N.S. \\
\hline & memory & 10 & 5 & $3.01 \mathrm{E}-04$ & & & N.S. \\
\hline & spatial memory of mice & 5 & 3 & $3.96 \mathrm{E}-04$ & & & N.S. \\
\hline & neurological process & 25 & 19 & $4.65 \mathrm{E}-08$ & 107 & 4 & 1.30E-03 \\
\hline & neurotransmission & 17 & 7 & $6.95 \mathrm{E}-07$ & 57 & & 1.30E-04 \\
\hline \multirow[t]{5}{*}{ Neurological Disease } & seizures & & & N.S. & 35 & 1 & 1.11E-04 \\
\hline & dyskinesia & & & N.S. & 76 & 2 & $1.86 \mathrm{E}-04$ \\
\hline & Huntington's disease & 18 & 11 & $2.11 \mathrm{E}-06$ & 75 & 1 & $2.06 \mathrm{E}-04$ \\
\hline & neurological disorder & 42 & 41 & $2.36 \mathrm{E}-06$ & 258 & 11 & 5.50E-03 \\
\hline & $\begin{array}{l}\text { neurodegeneration of } \\
\text { neurons }\end{array}$ & 8 & 3 & $2.75 \mathrm{E}-04$ & 27 & & 6.10E-04 \\
\hline
\end{tabular}

Gene expression data sets containing gene identity and corresponding expression values from an Illumina Technology analysis have been analyzed using the Ingenuity Pathway Analysis program. Out of 4795 eligible genes, the analysis generated lists of the most significant biological functions that are likely to be affected in anhedonic stressed or resilient stressed mice hippocampi, respectively. For selected detailed functions, the numbers of up-regulated and downregulated genes are shown, as well as the significance score of the change in expression calculated as p-value of a right-tailed Fisher exact test. N.S. indicates a non-significant test ( $p$-value $>1 \mathrm{E}-02$ ) 
psychological processes, such as cognition, learning and LTP are also affected.

Another study with our model revealed an overproduction of the enzyme COX-2 in the hippocampus of anhedonic that was not observed in the non-anhedonic group (Strekalova and Steinbusch, in preparation). Pre-treatment with a pharmacological blocker of this enzyme with food carried out through the entire period of chronic stress elicited similar antidepressant-like effects to those, which were evoked by citalopram in this study (Table 5). Both drugs prevented a stress-induced decrease in sucrose intake and preference, behavioural despair and impairment of cognitive deficit in the fear conditioning paradigm. These data are in line with growing evidence that along with monoamines, factors of inflammation play a crucial role in the mechanisms underlying anhedonia and depression [76,82-84]. Recently, it has been established that pro-inflammatory factors induce not only symptoms of behavioural sickness which resemble an anhedonic state, but are also implicated in the pathogenesis of major depression. We believe that altered production of COX-2 specifically, and the pharmacological sensitivity of the main read-outs in our model, can be considered as an evidence for such a link.

Together, our data suggest distinct molecular correlates of states of stress and stress-induced anhedonia in a proposed model. Similarly, studies in a social defeat paradigm in C57BL/6J mice demonstrated that susceptible and resilient individuals, which are distinct in scores of social avoidance and sucrose intake and preference, have differential levels of immediate early genes Arc and Zif268 in the frontal cortex, BDNF in the hippocampus and the ventral tegmental area and DeltaFosB in the nucleus accumbens [21,50-53]. Studies in Wistar rats showed distinct expression patterns of BDNF and vascular endothelial factor in the hippocampus [23]. Differential expression of AMPA receptors in the dorsal hippocampus was revealed between resilient and susceptible individuals in a social stress model in outbred mice [57]. Further studies are required to address key pathogenetic gene expression factors of resilience and susceptibility to a depressive syndrome precipitated by stress; such studies are under way.

\section{Limitations of the sucrose preference test in assessing} anhedonia in chronic stress paradigms

Several behavioural paradigms are currently used to measure sensitivity to reward in rodent chronic stress models. These include consumption of palatable solutions, progressive ratio responding, intracranial self-stimulation, novel-object place conditioning and conditioned place preference [36,61,85-87]. The sucrose/saccharine consumption free-access paradigm is probably the most extensively used method, as it is not too labour- or time-intensive, has high throughput and aritifacts related to learning, anxiety and locomotion are minimal with this model. Decreased intake and/or preference for palatable solutions is an overall validated behavioural measure of hedonic deficit $[9-13,87]$. Insufficient accuracy of the sucrose test in mice is, however, one of the key difficulties in measuring behaviour in chronic stress models of depression [14,32,38,39]. In mice, the sucrose test can typically reveal the differences between groups, but not between individual animals, and is generally considered to result in more variable outcome than in rats. A variety of sucrose test protocols have been proposed to overcome these inconveniences [88-93].

The species-specific physiological features of drinking behaviour and physical artifacts in its evaluation are believed to underlie the insufficient resolution of the sucrose test in mice $[14,32,35,39]$. In a series of experiments, we have identified factors of drinking behaviour in C57BL/6N mice, which may essentially interfere with the outcome of the standard free-choice, two-bottle sucrose test paradigm (Table 6). First, we found that individual mice of the tested strain showed a preference for drinking at one or the other corner of the cage. This preference was not related to any obvious external factors, e.g., source of noise or lighting in the room, as consumption of highly concentrated sucrose solution depended on its localization either in the preferred or non-preferred bottle position. Housing the mice with water on both sides of the cage abolished the side preference in drinking behaviour in some but not all animals. Switching the position of the bottles containing water or sucrose solution halfway through the test minimalised this confounding factor. Second, in C57BL/6N mice, one-bottle water tests revealed

Table 5 Effects of COX-2 inhibitor in mice subjected to chronic stress

\begin{tabular}{|c|c|c|c|}
\hline Changes versus non-stressed control & Stressed drug naive & Stressed Citalopram-treated & Stressed treated with COX-2 blocker \\
\hline Sucrose preference & $\downarrow$ & $\leftrightarrow$ & $\leftrightarrow$ \\
\hline Sucrose intake & $\downarrow$ & $\leftrightarrow$ & $\leftrightarrow$ \\
\hline Floating behavior & $\uparrow$ & $\leftrightarrow$ & $\leftrightarrow$ \\
\hline Contextual fear conditioning & $\downarrow$ & $\leftrightarrow$ & $\leftrightarrow$ \\
\hline Parameters of anxiety in elevated O-maze & $\uparrow$ & $\leftrightarrow$ & $\uparrow$ \\
\hline Percentage of anhedonic mice & above $60 \%$ & below $25 \%$ & below $25 \%$ \\
\hline
\end{tabular}

Chronic treatment with a COX-2 inhibitor during the course of chronic stress counteracted the development of hedonic deficit, behavioural despair, increased anxiety and cognitive impairment in a similar manner to citalopram. Arrows indicate an increase in the parameter $(\uparrow)$, a decrease $(\downarrow)$, or lack of significant changes in comparison to non-stressed control mice $(\leftrightarrow)$. 
Table 6 Factors of potential confounds in a free drinking two-bottle sucrose test

\begin{tabular}{|c|c|c|c|}
\hline Own behavioral data & $\begin{array}{l}\text { Source of } \\
\text { confounds }\end{array}$ & Preventing of confounds in testing & References \\
\hline $\begin{array}{l}\text { Sucrose solution intake is affected by a position of the bottle } \\
\text { on preferable or non-preferable side. Weeks of housing with } \\
\text { two bottles does not abolish side preference in drinking } \\
\text { behaviour }\end{array}$ & $\begin{array}{l}\text { Side preference in } \\
\text { drinking }\end{array}$ & $\begin{array}{c}\text { Switching of the bottles in a middle } \\
\text { of the test }\end{array}$ & {$[21,22,24,38,47,92]$} \\
\hline Individual patterns of absolute water intake in a 10-h test & $\begin{array}{l}\text { Large individual } \\
\text { variability in daily } \\
\text { drinking patterns }\end{array}$ & Prolonged testing & {$[38,47,89,92]$} \\
\hline $\begin{array}{l}\text { High variability in sucrose intake versus water intake in } \\
\text { sucrose-naïe mice }\end{array}$ & Neophobia & $\begin{array}{l}\text { Habituation to a sucrose solution } \\
\text { Sucrose preference as a measure of } \\
\text { hedonic sensitivity }\end{array}$ & {$[22,38,44,47,85,90-92]$} \\
\hline $\begin{array}{l}\text { Ceiling values of sucrose preference after massive experience } \\
\text { in sucrose ingestion }\end{array}$ & $\begin{array}{l}\text { Sensitization to a } \\
\text { sucrose taste }\end{array}$ & $\begin{array}{l}\text { Use of sucrose solution of low } \\
\text { concentrations }\end{array}$ & {$[24,38,47,87,88,93]$} \\
\hline High inter-individual variability in absolute intake of liquids & $\begin{array}{l}\text { Inter-individual } \\
\text { differences in } \\
\text { metabolic needs }\end{array}$ & $\begin{array}{c}\text { Use of a sucrose preference not } \\
\text { sucrose intake as a measure of } \\
\text { hedonic sensitivity }\end{array}$ & {$[25,38,44,47,85,87,92,93]$} \\
\hline
\end{tabular}

Studies revealed major sources of confounding factors in the commonly used mouse sucrose preference test. The application of testing conditions which minimize their impact were shown to be benefitial in recently published literature.

individual daily drinking patterns, specifically mice showed peaks in drinking behaviour during the 10-hour test period. Interestingly, temporal patterns in water intake correlated with mean volume of consumption. For example, animals with a peak in water intake $7.5 \mathrm{~h}$ after the beginning of the active phase of the animals' cycle had significantly higher values of total water intake than any other group. These data suggest that when analyzing drinking behaviour and sucrose preference, experiments should cover the periods of maximal liquid intake in all animals, as well as taking into account the relative parameters of preference in choice paradigms, rather than of absolute intake values. In addition, absolute consumption of palatable liquids can often be confounded by changes in the consumatory behaviour induced by deprivation of food and water, acute effects of stressors, altered metabolic needs in calories and water $[32,34,35,37]$. The greater variation in values of absolute intake of sucrose solution in comparison with those of sucrose preference, as shown by significant differences in variation $[38,85,87]$, additionally define sucrose preference as a parameter, which is least influenced by animals' individual drinking patterns.

Our experiments on mice naive to the taste of sucrose revealed remarkable diversity in animals' reactivity to a sweet taste, which ranged from almost no reaction to excessive sucrose consumption. Repeated exposure to sucrose abolished the first type of behaviour, suggesting that neophobia could underlie this response. A single pre-exposure of mice to concentrated sucrose, a procedure developed in a course of our studies, precluded large variability in their sucrose preference. In different studies, with repeated sessions of the sucrose test, preference and intake of sucrose solutions were found to increase substantially, suggesting that the results of testing in this paradigm depend on the animals' previous experience of sucrose consumption can increase sucrose intake and preference up to ceiling values decreases test's sensitivity $[38,47]$. This undesirable effect can be counter balanced by application of sucrose solutions of descending concentrations [45].

Our results confirm the findings of others, which demonstrate that in comparison to rats, mice generally demonstrate lower values of sucrose preference and sucrose intake, a pronounced neophobic behaviour during the very first exposure to a sucrose solution, essential inter-individual variability in sucrose preference and, especially, in absolute values of daily liquid intake [11-13,87-93]. Together, the above data show that sucrose preference is a parameter of the sucrose test and is more appropriate than absolute sucrose intake for the analysis of inter-individual differences in hedonic sensitivity in mice. Further, bottle-position preference in mouse drinking behaviour and neophobia together with other factors, may be the cause of essential physiological artifacts in evaluating the sucrose test.

\section{Correcting for limitations in the sucrose preference test in chronic stress-induced anhedonia}

We have undertaken several procedural modifications in order to eliminate the above behavioural artifacts. With our proposed protocol, mice are given a free choice between two bottles for 8 -24 hours, one with $1 \%$-sucrose solution and another with tap water; the position of the bottles in the cage is switched halfway through this period. At no point during or prior to this are mice deprived of food or water. To minimize the spillage of liquids during the sucrose test, bottles are filled in advance and kept in an up-side-down position for at least 12 hours prior to testing. In order to balance the air temperature between the room and the drinking bottles, they are kept in the 
same room where the testing takes place. This prevents liquid leakage resulting from increased air temperature and pressure inside the bottles, when they are filled with liquids which are cooler than the room air.

The consumption of water, sucrose solution and total intake of liquids is estimated simultaneously in the control and experimental groups by weighing the bottles. In order to decrease variability in sucrose consumption during the very first sucrose test (baseline measurement), a day before, animals are allowed to drink a $2.5 \%$ sucrose solution in a one-bottle paradigm for 2 hours. The preference for sucrose is calculated as a percentage of the consumed sucrose solution from the total amount of liquid drunk by the formula:

Sucrose Preference $=$ V $($ Sucrose solution $) / V($ Sucrose solution $)+V($ Water $) \times 100 \%$

We found that with this method, the error of measurement does not exceed $0.1 \mathrm{ml}$. This appears to greatly enhance the resolution of the test and more specifically assess hedonic state that takes into account inter-individual variability.

\section{Submissive traits predict stress-induced anhedonia in C57BL6/N mice}

A number of studies have shown that it is possible to predict inter-individual variability, in terms of the stress response, by observing an animal's baseline behaviour. Specifically, animals that show high anxiety $[41,60,63]$, low open field locomotion [30,94], freezing response in averse conditions [42] and decreased exploratory behavior [25,43] will often have a different stress response to their 'normal' littermates. This phenomenon is attracting the attention of researchers and becoming broadly implemented in fundamental and industrial psychopharmacological research. In our experiments, male social behaviour was shown to predict an individual susceptibility to stress-induced anhedonia in mice: individuals with submissive social traits were found to be more vulnerable to the anhedonic state [44-47]. During a 4-week stress induction period, anhedonia was found to occur earlier in all submissive animals. In one study, after only 3.5 weeks, $100 \%$ of submissive mice exhibited lowered sucrose preference $(<65 \%)$ and matched a given criterion of anhedonia; only $16.6 \%$ of aggressive mice that had undergone the same stressors exhibited the criteria for anhedonia at this stage [44]. The ethological analysis of more than thirty parameters of social behavior in a resident-intruder test, performed with our stress model, revealed reduced scores in aggressive and dominance behaviours in mice predisposed to stress-induced anhedonia [95]. A number of studies have shown that animals with subdominant behavioural characteristics will most frequently exhibit low sucrose preference and anhedonia in similar social defeat models $[14,21,62,96-99]$. The variability in social traits, which is related to the animal's individual ability to cope with environmental stressors, can be considered as a biological factor of species' adaptation and survival. It can be of even higher significance when animals are placed in stressful conditions and, therefore, of evolutionary advantage in general. Recently identified epigenetic molecular mechanisms are suggested to underlie the distinct response of individual animals to environmental challenges $[9,94,100]$.

In our stress paradigm, a resident-intruder test was adapted from the procedure originally proposed by Krsiak and co-authors $[101,102]$. Initially, the protocol employs a qualitative criterion of differentiation into submissive vs. non-submissive mice, defined as an absence or presence of attacks towards the partner, respectively. In this test, male mice (C57/BL6N - intruders), after being isolated for 3-5 weeks, and when confronted in a neutral cage with another male mouse which had been group-housed (CD1 - residents), will either show aggressive (non-submissive), timid (submissive) or social behaviour. Aggressive activities of both resident and intruder are characterized by attack and aggressive unrest, frequently accompanied by tail rattling. Timid activities consist of alert posture, escape and defence and are never accompanied by aggressive reactions (attacks). Social behaviour includes social sniff and 'climb and follow', this type of social behaviour excludes attacks between the partners; in our study this behaviour was categorized as non-definable with regard to social submissiveness. A manifestation of submissive and aggressive types of social behaviour in C57BL/6N mice was found to appear irrespective of social traits of CD1 counter partners. According to our data, testing procedures did not induce depressive-like behaviours in the forced swim or sucrose preference tests. Group-housing of male C57BL/6N mice is known to result in aggressive behaviour between cage mates that, importantly, enhances a variability in anxietyrelated and a number of other behaviours, as well as having a significant impact on the stress response. We therefore chose to test animals from experimental groups, using them as intruders in a resident-intruder test, thus avoiding the undesirable effects of group housing. While it is more usual to analyze the resident animal in this paradigm, we believe that our protocol of testing social behaviour allowed us to preclude major artifacts in comparing animals from anhedonic and non-anhedonic groups.

Interestingly, in populations with an initially low percentage of submissive animals (15-20\%), all submissive mice develop anhedonia. In populations with a high percentage of submissive individuals ( $>50 \%)$, the percentage of nonsubmissive (dominant or aggressive) animals susceptible to anhedonia is significantly lower in comparison to a submissive cohort of mice. Remarkably, social characteristics of animal batches, such as a percentage of aggressive mice, 
were found to be related to behavioural patterns during stress. For example, changes in parameters such as sucrose intake and preference, and total liquid intake during different phases of the course of stress exposure were observed over a several years in our lab, under identical experimental conditions [39,47]. For instance, in populations with an initially low percentage of submissive animals, statistically significant decreases in sucrose preference in the stressed group occur at 3.5 weeks after introduction of the stressor. Interestingly, in these animals, stress exposure causes an increase in sucrose intake and preference at the beginning of the stress procedure, and leads to a slight elevation of water intake. In contrast, in experimental groups containing high percentage of submissive individuals $(>50 \%)$ the drop in sucrose preference is detected much earlier, after 2.5 weeks of stress; these animals demonstrate an increase in sucrose intake and sharp elevation of water consumption [Figures 1 and 2B; [44,48]]. Over our 6 years of studying them, the $\mathrm{C} 57 \mathrm{BL} / 6 \mathrm{~N}$ strain of mice have shown a remarkable range, from $15-85 \%$, in the proportion of individuals with submissive social characteristics.

Taken together, these data suggest that initial populations with unbalanced social traits could lead to different susceptibilities in terms of the chronic stress model, and may be one of the sources of unstable reproducibility. Our studies have shown that, in terms of development of anhedonia, no differences in initial open field, exploratory rearing, step-down avoidance, novel object or anxiety-like behaviours were exhibited between mice from anhedonic and non-anhedonic groups [38,39,44-49]. These data are not always consistent with results published by other groups, which, for example, found a correlation between initial elevated anxiety-like behaviour and enhanced stress-response $[41,63]$. The discrepancy between this and our data could be explicated by differences in substrains used and protocols of testing anxiety-like behaviours. Others, however, have largely supported our findings [21] by showing a lack of differences in various behavioural parameters and baseline sucrose intake and preference between animals from anhedonic and non-anhedonic groups. We believe that in general, balancing of percentage of animals upon a parameter, which is predictive for individual susceptibility to a depressive-like state in any particular chronic stress depression model, can greatly help increase its reliability, especially when the testing of potential anti-depressant treatment is involved.

\section{Identifying and compensating for behavioural artifacts caused by stress-induced hyperlocomotion}

Hyperlocomotion as an increase of a distance traveled by an animal over a time span is not uncommonly seen in chronic stress experiments. On another hand, many studies using chronic stress models of depression showed abnormal changes in rodents' behavior, which contradict well documented profiles of states of stress and depression in animals $[13,14]$. These changes are often called "paradoxical" or "anomalous" since they are opposite to the general known patterns of behavioural inhibition, impaired coping and increased scores of anxiety observed in patients with stress-related disorders and respective pre-clinical paradigms. For example, the chronic mild stress procedure was shown to not affect or to increase anxiety-like behaviours, i.e. time spent in anxiety-related areas of the elevated plus maze and dark/light box and to reduce immobility time in forced swimming tests in mice [103-107]. Exposure to a chronic stress was shown to lead to increased ambulation in the open-field test in mice [28]. Taking into account the aforementioned data from the literature, as well as our own results, which demonstrated drastic increases in speed and total path in the open-field, anxiolytic-like changes in the dark/light and elevated $\mathrm{O}$-maze paradigms alone with reduced duration of floating in the forced swim test in chronically stressed mice (Table 7), we suggest this hyperlocomotion is an non-specific consequence of chronic stress and is triggered by the stressful procedure of testing. Thus, reduction of the stress impact of testing conditions, e.g., diminishing light intensity should be considered as an important pre-requisite of behavioral analysis in the chronic stress models. These findings were implemented in our behavioural protocols in which we were using "mild" conditions of testing with low stress impact [108]. We believe this was a key factor in enabling us to identify consistent behavioural correlates of anhedonia in our model.

Recent studies described similar phenomenon in several laboratory mouse strains [109-111]. While various effects of chronic stress on general locomotion in rodents were described [34,96,112-114,1115], lighting conditions employed during testing were reported to be a significant factor of general activity in the stressed animals [116-118]. We believe that stress-induced hyperactivity is a typical phenomenon in chronically stressed C57BL/6N mice and is potentially a major source of artifacts in behavioural analysis of chronic stress data and that this can explain previously reported contradictions resulting from similar paradigms.

\section{Increased liquid intake and home-cage locomotion in anhedonic versus non-anhedonic mice: indication of an elevated stress-response?}

Stress-induced increases in sucrose and water intake in mice and rats exposed to a prolonged stress have been documented elsewhere $[21,34,119,120]$. Parallels have been made in the literature between these signs of elevated consummatory behaviour in stressed animals and other indicators of behavioural invigoration, e.g. enhanced swim scores, excessive grooming, increased 
activity in anxiety paradigms and in other tests [121-123]. Apart from general behavioural invigoration and an increase in consumption scores, the augmentation of general liquid intake observed in chronic stress paradigms is believed to result from a stress-induced polydipsia, increased metabolic needs, diabetes mellitus and altered hormone secretion from both the hypothalamus and hypophysis $[21,124,125]$. Our studies revealed drastic changes in water and sucrose solution consumption as well as home cage locomotion during the course of the chronic stress procedure in C57BL/6N mice. Analysis of animals from the anhedonic and non-anhedonic groups at different phases of stress, and after its termination revealed distinct patterns of dynamics within these parameters $[39,44,45,47]$.

Our extensive experience with the chronic stress model of depression has repeatedly shown that anhedonic mice develop increased sucrose preference and intake between days 14-21 of a 28 day paradigm. This effect is pronounced and of significant duration in anhedonic animals but is transient in non-anhedonic groups (Figure 2, adapted from [45]). Similarly, total liquid intake is also increased in both groups but anhedonic animals maintain this change over a longer period than their non-anhedonic littermates. The increased water intake in anhedonic animals lasts for several weeks after the termination of chronic stress; non-anhedonic animals, however, exhibited normal liquid consumption during the after-stress period (Figure 3; adapted from [45]). Of note, chronic administration of antidepressants citalopram and imipramine, applied during and after chronic stress, reduced stressinduced increase in water consumption in our model [45].

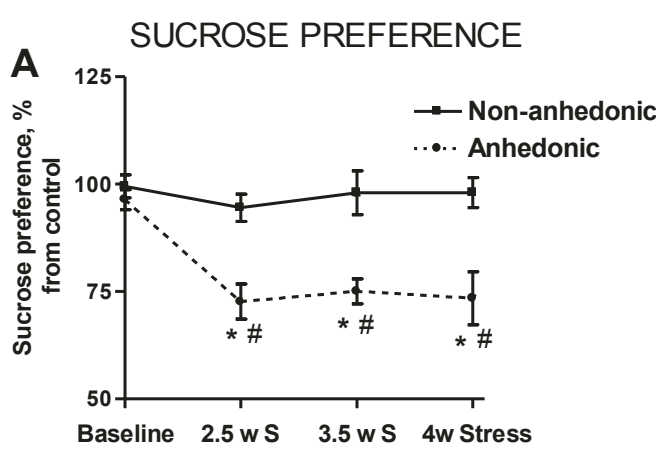

C

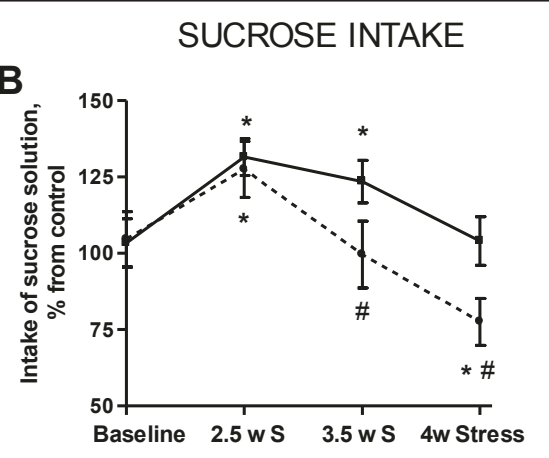

D

\section{WATER INTAKE}

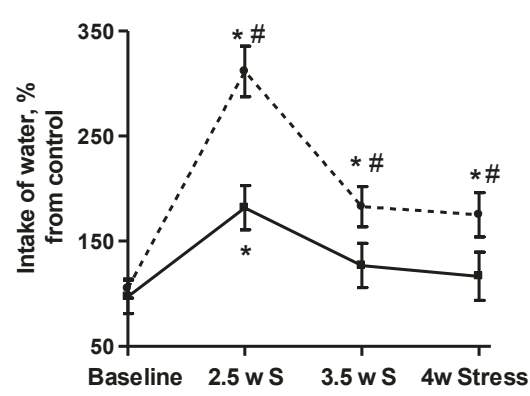

TOTAL LIQUID INTAKE

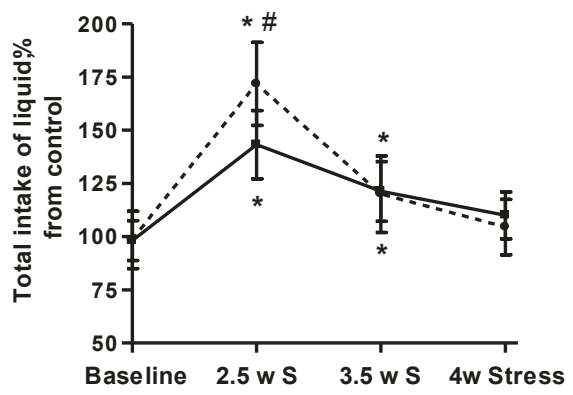

Figure 2 Differential stress-induced changes in the sucrose test parameters in anhedonic and non-anhedonic mice. (A) Sucrose preference in the anhedonic group is significantly lower than in non-anhedonic and control mice after 2.5, 3.5 and 4 weeks of stress. (B) Sucrose intake in the anhedonic group is significantly increased after 2.5 weeks of stress and significantly decreased after 3.5 weeks of stress (vs. non-anhedonic group) and after 4 weeks of stress (vs. control and non-anhedonic group). Non-anhedonic mice show elevated sucrose intake after 2.5 and 3.5 weeks of stress. (C) Water intake is elevated in the anhedonic animals after $2.5-4$ weeks of stress (vs. control and nonanhedonic group). In the non-anhedonic group; water intake is increased after 2.5 weeks of stress as compared to control. (D) Total liquid intake is elevated both in the anhedonic and in non-anhedonic animals after 2.5 and 3.5 weeks of stress (vs. control group). After 2.5 weeks, anhedonic mice show significantly higher total liquid intake than non-anhedonic mice. Parameters of the sucrose test are expressed as a percentage of the mean values of the control group, and compared between anhedonic (dashed line) and non-anhedonic (plain line) groups during a 4-week stress procedure as mean \pm (SEM) ( ${ }^{*} p<0.05$ vs. control group; $\# p<0.05$ vs. non-anhedonic group; Mann-Whitney). 
Table 7 Identifying and compensating for behavioural artifacts caused by stress-induced hyperlocomotion

\begin{tabular}{llllll}
\hline & \multicolumn{2}{l}{ Anxiety-like behavior } & Floating in FST & & Open field locomotion \\
\cline { 2 - 6 } & Standard protocol & Mild protocol & Standard protocol & Mild protocol & Bright/modest lighting \\
\hline Short stress & $\uparrow$ & $\uparrow$ & $\leftrightarrow$ & $\leftrightarrow$ & $\leftrightarrow$ \\
\hline Chronic stress & $\downarrow$ & $\uparrow$ & $\downarrow$ & $\uparrow$ & $\uparrow$ \\
\hline Chronic stress + diazepam lighting \\
\hline
\end{tabular}

Reduction in illumination, application of "mild" testing conditions or bolus diazepam injection preclude hyperlocomotion and "anomalous" behaviour in anxiety and forced swim tests in chronically stressed mice. Mice subjected to short stress (1 week duration) do not exhibit "anomalous" behaviour. Arrows indicate an increase in the parameter $(\uparrow)$, a decrease $(\downarrow)$, or lack of significant changes in comparison to non-stressed control mice $(\leftrightarrow)$.

Increased intake of liquids in mice from the anhedonic group was paralleled in our paradigm by sharp increases in home-cage horizontal activity, which was not observed the non-anhedonic group [47]. The latter behaviour was studied using the System and software for Automatic Measurement of Animal Behaviour (SAMAB), where mice were housed individually in specialized cages with infrared detection of horizontal movement.

Mean duration of movement was significantly elevated, in anhedonic animals only, during the dark phase of the day/night cycle between days 14 and 21 during the stress procedure and for at least 14 days after termination of the procedure (Figure 4A); no differences between the groups are observed during the light phase (Figure 4B).

While the nature of the elevated intake of palatable solutions during chronic stress is unclear, several reports suggest that consumption of sweetened solutions can evoke an antidepressant-like effect in rodents [13]. Interestingly, mice from a group susceptible to stress-induced social avoidance/anhedonia were shown to have higher scores of conditioned place conditioning in comparison to resilient mice [21]. This led to speculation that enhanced sucrose

\section{A SUCROSE PREFERENCE}

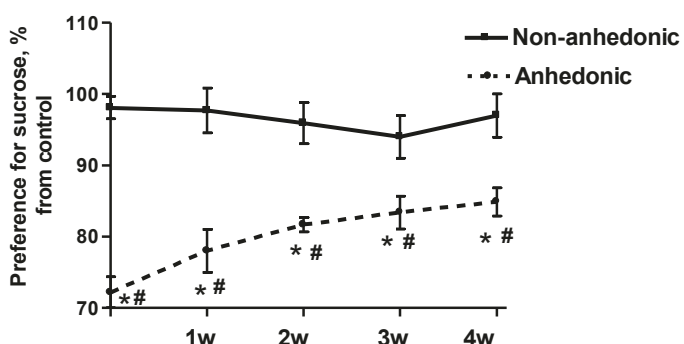

C WATER INTAKE

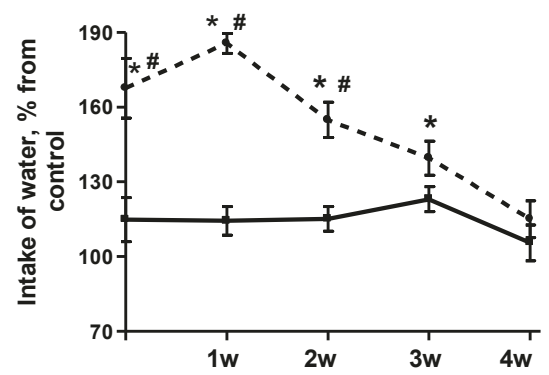

B SUCROSE INTAKE

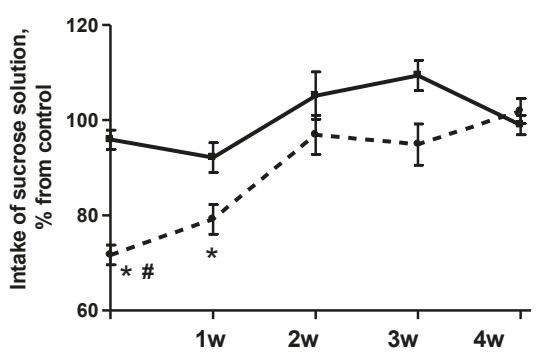

D TOTAL LIQUID INTAKE

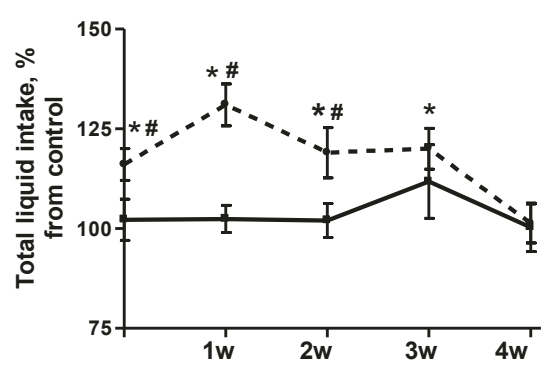

Figure 3 Dynamics of the sucrose test parameters recovery in anhedonic and non-anhedonic mice. Parameters of the sucrose test were expressed as a percentage of mean values of the control group, and compared between anhedonic (dashed line) and non-anhedonic (plain line) groups during a 4-week stress procedure ( ${ }^{*} p<0.05$ vs. control group; \# $p<0.05$ vs. non-anhedonic group; Mann-Whitney). (A) Sucrose preference in the anhedonic group is significantly lower than in the non-anhedonic and control mice throughout the entire experiment. (B) Sucrose intake in the anhedonic group is significantly decreased after the termination of stress (vs. control and non-anhedonic group) and during week 1 of the stress-free period (vs. control group). (C, D) Water consumption and total liquid intake are elevated in the anhedonic animals up to 3 weeks after termination of stress as compared to control, and up to 2 weeks when compared to non-anhedonic mice. Data are expressed as mean $\pm($ SEM). 
A

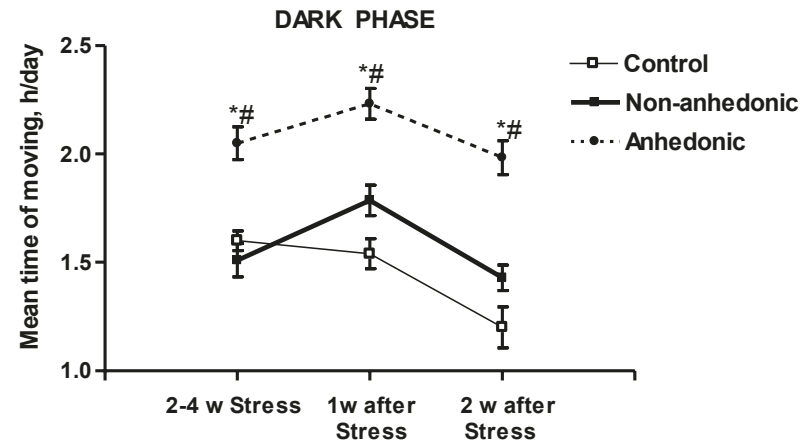

B

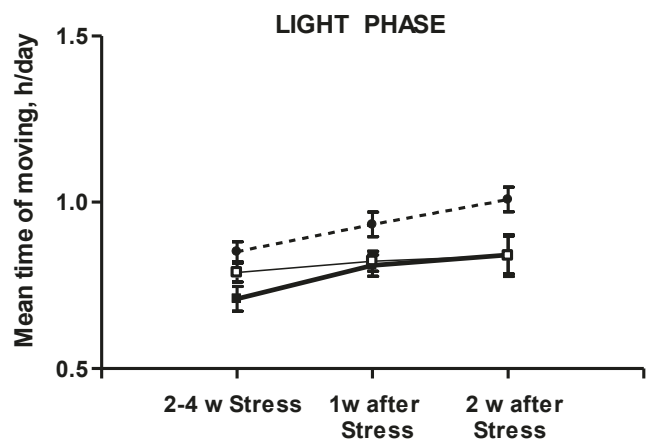

Figure 4 Anhedonic mice display lasting increases in home cage activity during the dark phase of the day. (A) During the dark phase of the diurnal cycle, mean time of horizontal movement of the anhedonic group (dashed line) is significantly elevated during 2 nd-4th weeks of stress, and during weeks 1 and 2 after the termination of the stress procedure, as compared to the non-anhedonic (plain thick line) and control (plain thin line) groups ( ${ }^{*} p<0.05$ vs. control group and \# $p<0.05$ vs. non-anhedonic group; Mann-Whitney). This parameter does not change in the non-anhedonic group throughout the entire experiment ( $p>0.05$ vs. control group). (B) During the light phase of the day, no difference between the groups in home cage activity is observed ( $p>0.05$ ). Data are expressed as mean \pm (SEM).

intake and preference in chronically stressed animals might be "adaptation" to stress at its early stages. As such, their increase in mice from an anhedonic group might reflect a "hyperadaptation" to stress in this population, and that the development of anhedonia at the late stage of stress can manifest itself as a state of a "distress" in this subgroup.

Both pronounced elevation of water intake and enhanced home cage locomotion in anhedonic animals may result from general sympathetic activation, induced by chronic stress, and thus, reflect a pronounced response to stress in these animals $[21,126]$. Our results also suggest that stress-induced anhedonia in the current mouse model is accompanied by an altered pattern of the day/night activity, which correlates with compromised sleep-wake patterns in depressed patients [127], and which is not seen in stressed animals without hedonic deficit. These data are in line with other studies which found stress-induced hypertherimia and a decrease in circadian amplitude in a subgroup of mice with a depressive-like state in a social defeat model [21]. Together, differential patterns of liquids intake and home-cage locomotion in anhedonic versus non-anhedonic mice may be reflective of a higher stress susceptibility in the first cohort of animals.

\section{The effects of citalopram in anhedonic and non- anhedonic mice}

Recent studies suggest that chronic SSRI treatment in mice resilient and susceptible to social defeat stress exerts distinct physiological and molecular effects on the ventral tegmental area and the medial prefrontal cortex $[23,53,54,128,129]$. In line with these findings, pharmacological validation of a proposed model of stress-induced anhedonia with a "post-stress" administration of citalopram demonstrated its differential effects in anhedonic and non-anhedonic groups. In one of the studies, exposure of animals to chronic stress was followed by citalopram delivery via the drinking solution $(15 \mathrm{mg} / \mathrm{kg} /$ day $)$ for four weeks. Sucrose preference and body weight were monitored weekly in control, anhedonic and non-anhedonic mice [45]. Sucrose intake and preference increased in citalopram-treated, but not non-treated anhedonic mice on the 4th week of the dosing schedule; non-anhedonic and control mice showed no changes in sucrose preference at any time point (Figure 5A, adapted from [45]). Multiple regression analysis showed that restoration of a preference for sucrose in the anhedonic group was mostly due to a several fold elevation of sucrose ingestion, a phenomenon typical for prolonged treatment with antidepressants of various classes [11-14]. Interestingly, while at this time point of the experiment, mean sucrose consumption in the non-treated anhedonic group was not different from the values of non-treated control and non-anhedonic groups, citalopram essentially affected sucrose intake exclusively in anhedonic animals (Figure 5B). In the forced swim test, anhedonic mice treated with an antidepressant, demonstrated a decrease in duration of floating behaviour, which was elevated in the non-treated anhedonic group. Of note, chronic administration of citalopram did not affect floating of the non-anhedonic animals and nonsignificantly elevated this parameter in non-stressed control mice. Together, these data suggest that the occurrence of a depressive-like state is a pre-requsite of animals' sensitivity to the action of antidepressants in a chronic stress paradigm. More studies are required to elucidate the physiological basis of selective effects of citalopram on depressive-like features in stressed anhedonic mice. 

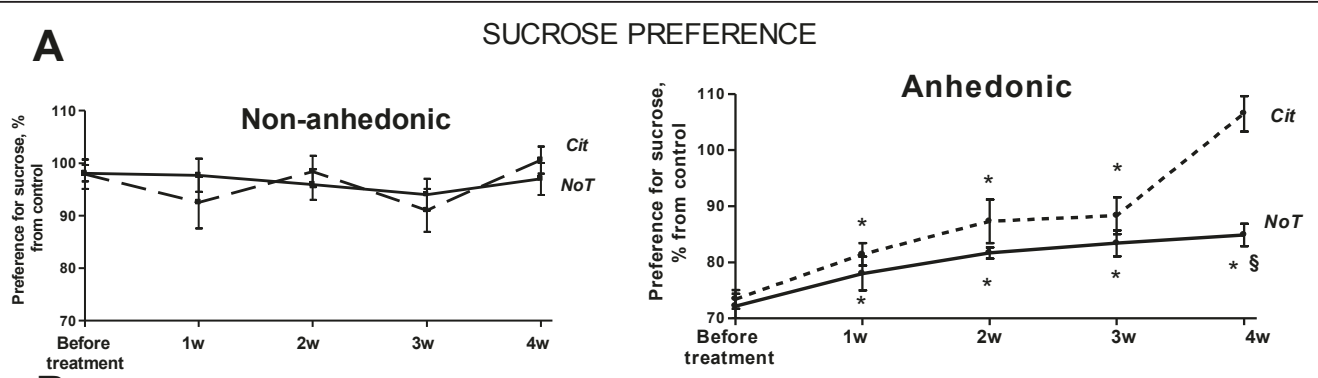

B

SUCROSE INTAKE
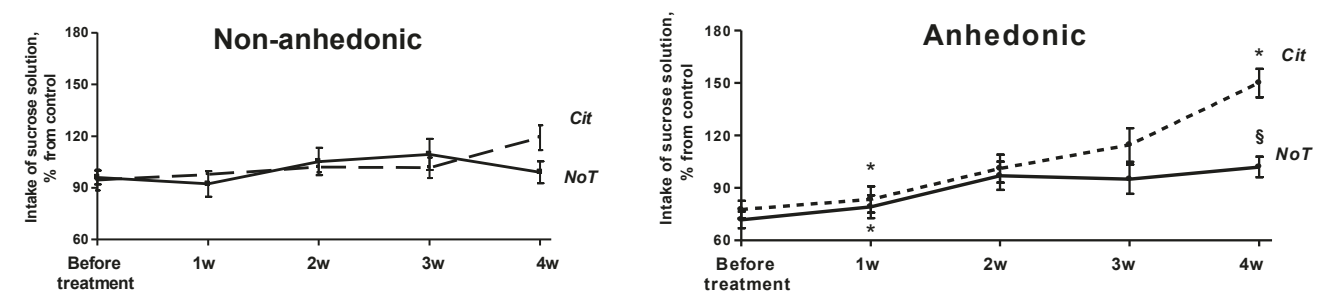

C

WATER INTAKE
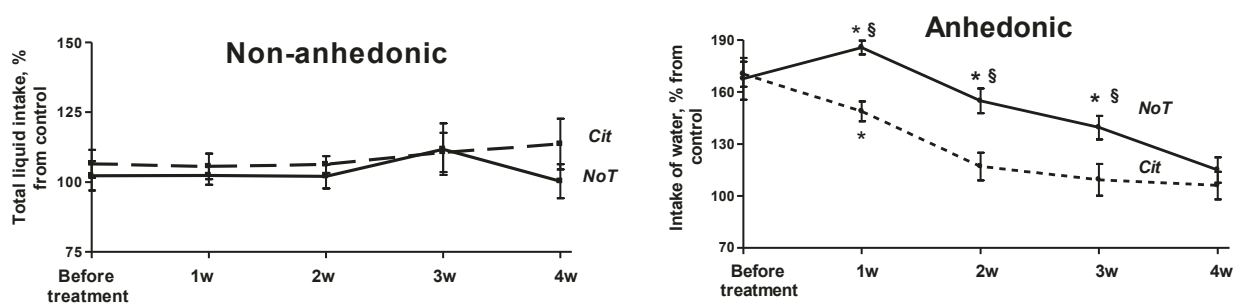

D

TOTAL LIQUID INTAKE
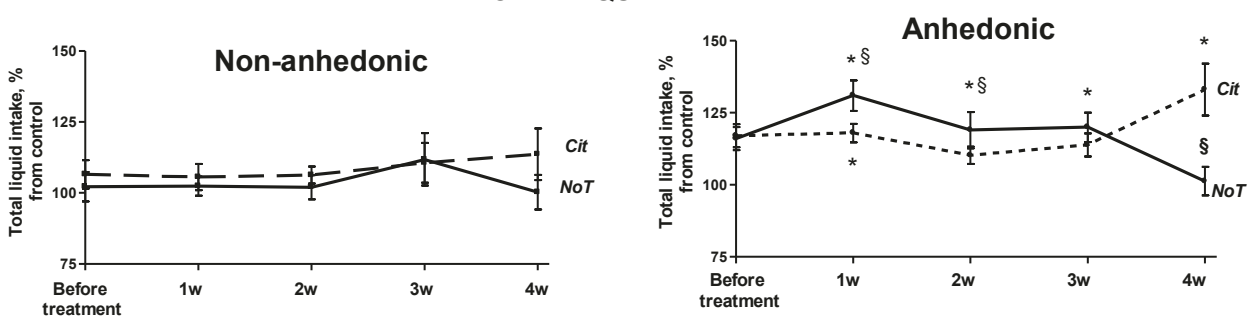

E

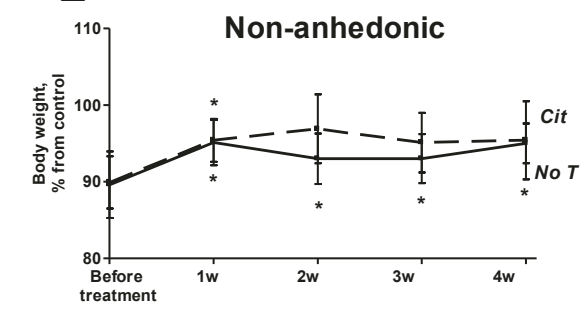

BODY WEIGHT

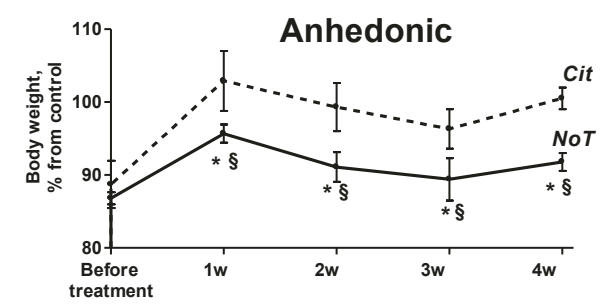

Figure 5 Effects of citalopram on sucrose test parameters and body weight in anhedonic and non-anhedonic mice. (A-E) Data are expressed as a percentage of the control and presented as medians \pm interquartile intervals. Plain lines indicate non-treated groups, dashed lines indicate citalopram-treated groups. NoT: non-treated group; Cit: citalopram-treated group $\left({ }^{*} p<0.05\right.$ vs. control group; $\S p<0.05$ vs. citalopram-treated anhedonic mice). 
Experiments with various methods of citalopram administration indicated that in anhedonic animals, chronic administration of drug reduced water intake, which was enhanced in this group of mice, and did not affect this parameter in the non-anhedonic animals (Figure 5C). Interestingly, anhedonic animals from the citalopram-treated stressed group had a higher average body weight than non-anhedonic animals from the same group (Figure 5E). Citalopram restored the body weight of anhedonic mice after the 1st week of post-stress treatment but did not have such an effect in non-anhedonic animals. During weeks 2-4, body mass of the latter group was lower, although not significantly, than in control and citalopramtreated anhedonic aniamls. Prior to citalopram treatment, both anhedonic and non-anhedonic animals exhibited similar patterns of weight loss compared to controls. Restoration of body weight by antidepressant treatment, particularly citalopram, in animal models of depression has been shown to to accompany recovery from a depressive-like state [130]. The distinct effects of citalopram on body weight in anhedonic and non-anhedonic mice may be related to the metabolic differences between these animals: repeated experiments with our model have revealed a general higher baseline body mass in anhedonic than in non-anhedonic animals (Strekalova, unpublished results). These results suggest that citalopram is capable of altering a number of variables in anhedonic animals. This provides more refined analysis of the effects of antidepressant treatment with respect to the states of stress and anhedonia.

\section{Conclusions}

In line with available literature, our studies identified distinct physiological and molecular profiles of anhedonic and non-anhedonic groups of mice subjected to stress. As such, the proposed mouse paradigm and other models which enable the segregation of subpopulation of animals with and without a depressive-like pattern can be a tool for addressing the biology of individual susceptibility and resilience to depression. Besides that, this approach provides other valuable advantages in modelling of depressive disorder in animals, as for instance, it allows the differentiation between core and subsidiary depressive features and let to simulate the co-morbidity of depression and other stress-related disorders, e.g., anxiety diseases $[78,79,131,132]$. This opens new possibilities in pre-clinical studies aimed at the differentiation between therapeutic effects of antidepressants to depression symptoms and other concominant pathological changes. We believe that data on distinct sensitivity to an antidepressant treatment of stressed mice with and without depressive-like syndrome argue for the validity of our paradigm in mimicking such clinical aspects of the disorder.

We feel the importance of emphasizing the fact that the use of internal control in a chronic stress depression paradigm and behavioural assessment of the validity of its definition became possible only when the methodology of chronic stress model in tested strain of mice was essentially modified. These modifications mostly concern (1) the sucrose test protocol in mice, the accuracy of which could be sharply increased to allow distinguish inter-individual differences in the occurrence of signs of anhedonia, and (2) the identification and overcoming of confounds in behavioral testing related to stress-induced hyperlocomotion. Another feature which appeared to be important for more accurate group comparison with the chronic stress model is their balancing upon (3) a percentage of individuals with submissive and dominant social traits, which predicted a susceptibility to a stressed-induced anhedonia in employed strain.

Together, results discussed here argue for the use of a subgroup of individuals who are negative for the induction of a depressive phenotype with experimental paradigms of depression as an internal control, for more advanced modeling of this disorder in animals.

\section{Acknowledgements}

The work on this review was supported by the transnational University Limburg (tUL) foundation, the "NanoBioPharmaceutics" project (the sixth Framework Programme for Research and Technological Development of the EC: EC-FP6), ISAO (N 09501 to T.S), NARSAD (YIA to T.S.), RFBR 11-04-01411 and Fundação para a Ciência ea Tecnologia (FCT), Portugal. All experiments were carried out in accordance with the European Communities Council Directive for the care and use of laboratory animals following approval by the local governmental bodies for animal care and welfare (Regierungspräsidium Karlsruhe, N 35-9185.81/G-48/04; DGV 08; DEC-UM 2009-109). Reproduction of the material presented in this review is permitted by Nova Science Publishers, Inc., 2008 and Lippincott Williams \& Wilkins, Behavioral Pharmacology, Strekalova T, Gorenkova N, Schunk E, Dolgov O, Bartsch D. Selective effects of citalopram in the mouse model of stress-induced anhedonia with control effects for chronic stress. 2006;17: 271-287 and by Macmillan Publishers Ltd: Neuropsychopharmacology, Strekalova T, Spanagel R, Bartsch D, Henn FA, Gass P. Stressed-induced anhedonia in mice is associated with deficits in forced swimming and exploration. Neuropsychopharm 2004; 11: 2007-2017.

\section{Author details}

'Department of Neuroscience, Faculty of Health, Medicine and Life Sciences, Maastricht University, Maastricht, Netherlands. ${ }^{2}$ Center of Environmental Biology, Faculty of Sciences, Lisbon University, Lisbon, Portugal. ${ }^{3}$ Department of Pharmacology, Oxford University, Oxford, UK. Institute of General Pathology and Pathophysiology, Russian Academy of Medical Sciences, Moscow, Russia. ${ }^{5}$ Northwestern University, Feinberg School of Medicine, Lurie Cancer center, Chicago, IL, USA. ${ }^{6}$ GIGA-Neuroscience, University of Liege, Liege, Belgium.

\section{Authors' contributions}

TS carried out behavioral studies, drafted the manuscript and coordinated manuscript preparation. YC helped with the molecular genetic studies and drafted the manuscript. NK participated in the analysis of gene expression studies and helped to draft the manuscript. MB took part in the gene expression data analysis. DM performed the treatment of raw gene expression data and statistical analysis. PL carried out IPA analysis of gene expression data and drafted the manuscript. HS participated in the design of the studies and its coordination and helped to draft the manuscript. All authors read and approved the final manuscript.

\section{Competing interests}

The authors declare that they have no competing interests. 
Received: 18 July 2010 Accepted: 27 April 2011 Published: 27 April 2011

\section{References}

1. Lassnig R, Hofmann P: Life crisis as a consequence of depression and anxiety. Wien Med Wochenschr. [Article in German] 2007, 157:435-444.

2. Lexis $M$, Jansen $N$, van Amelsvoort $L$, van den Brandt $P$, Kant I: Depressive complaints as a predictor of sickness absence among the working population. J Occup Environ Med 2009, 5:887-895.

3. Kessler R, Chiu W, Demler O, Merikangas K, Walters E: Prevalence, severity and comorbidity of 12-month DSM-IV disorders in the National Comorbidity Survey Replication. Arch Gen Psychiatry 2005, 62:617-627.

4. Khandker R, Kruzikas D, McLaughlin T: Pharmacy and medical costs associated with switching between venlafaxine and SSRI antidepressant therapy for the treatment of major depressive disorder. J Manag Care Pharm 2008, 14:426-441.

5. Greenberg $P$, Corey-Lisle P, Birnbaum H, Marynchenko M, Claxton A: Economic implications of treatment-resistant depression among employees. Pharmacoeconomics 2004, 22:363-373.

6. Hamilton M: Development of a rating scale for primary depressive illness. Br J Soc Clin Psychol 1967, 6:278-296.

7. Klein D: Endogenomorphic depression. A conceptual and terminological revision. Arch Gen Psychiatry 1974, 31:447-454.

8. Insel TR: From animal models to model animals. Biol Psychiatry 2007, 15:1337-1339.

9. Krishnan V, Nestler EJ: Animal Models of Depression: Molecular Perspectives. Curr Top Behav Neurosci 2011.

10. Cryan J, Holmes A: The ascent of mouse: advances in modelling human depression and anxiety. Nat Rev Drug Discov 2005, 4:775-790.

11. Willner P: Animal models as simulations of depression. Trends Pharmacol Sci 1991, 12:131-136.

12. Willner P: Validity, reliability and utility of the chronic mild stress model of depression: a 10-year review and evaluation. Psychopharm 1997, 134:319-329.

13. Willner P: Chronic mild stress (CMS) revisited: consistency and behavioural-neurobiological concordance in the effects of CMS. Neuropsychobiol 2005, 52:90-120.

14. Anisman H, Matheson K: Stress, depression and anhedonia: caveats concerning animal models. Neurosci \& Biobehav Rev 2005, 29:525-546.

15. Katz R: Animal models and human depressive disorders. Neurosci Biobehav Rev 1981, 5:231-246.

16. Willner P, Towell A, Sampson D, Sophokleous S, Muscat R: Reduction of sucrose preference by chronic unpredictable mild stress, and its restoration by a tricyclic antidepressant. Psychopharmacology (Berl) 1987, 93:358-364.

17. Katz R: Animal model of depression: pharmacological sensitivity of a hedonic deficit. Pharmacol Biochem Behavior 1982, 16:965-968.

18. Moreau J, Scherschlicht R, Jenck F, Martin J: Chronic mild stress-induced anhedonia model of depression; sleep abnormalities and curative effects of electroshock treatment. Behav Pharmacol 1995, 6:682-687.

19. Baker S, Kentner A, Konkle A, Santa-Maria Barbagallo L, Bielajew C: Behavioral and physiological effects of chronic mild stress in female rats. Physiol Behav 2006, 87:314-322.

20. Grønli J, Murison R, Bjorvatn B, Sørensen E, Portas CM, Ursin R: Chronic mild stress affects sucrose intake and sleep in rats. Behav Brain Res 2004, 150:139-147.

21. Krishnan V, Han MH, Graham D, Berton O, Renthal W, Russo S, Laplant Q, Graham A, Lutter M, Lagace D, Ghose S, Reister R, Tannous P, Green T, Neve R, Chakravarty S, Kumar A, Eisch A, Self D, Lee F, Tamminga C, Cooper D, Gershenfeld H, Nestler E: Molecular adaptations underlying susceptibility and resistance to social defeat in brain reward regions. Cell 2007, 131:391-404

22. Pothion S, Bizot J, Trovero F, Belzung C: Strain differences in sucrose preference and in the consequences of unpredictable chronic mild stress. Behav Brain Res 2004, 155:135-146.

23. Bergström A, Jayatissa MN, Thykjaer T, Wiborg O: Molecular pathways associated with stress resilience and drug resistance in the chronic mild stress rat model of depression: a gene expression study. J Mol Neurosci 2007, 33:201-215.

24. Schmidt MV, Sterlemann V, Müller MB: Chronic stress and individual vulnerability. Ann N Y Acad Sci 2008, 1148:174-183.
25. Li Y, Zheng $X$, Liang J, Peng Y: Coexistence of anhedonia and anxietyindependent increased novelty-seeking behavior in the chronic mild stress model of depression. Behav Processes 2010, 83:331-339.

26. Larsen MH, Mikkelsen JD, Hay-Schmidt A, Sandi C: Regulation of brainderived neurotrophic factor (BDNF) in the chronic unpredictable stress rat model and the effects of chronic antidepressant treatment. J Psychiatr Res 2010, 44:808-16, 2010.

27. Elizalde, N, Gil-Bea, F, Ramírez, M, Aisa, B, Lasheras, B, Del Rio J, Tordera, R: Long-lasting behavioral effects and recognition memory deficit induced by chronic mild stress in mice: effect of antidepressant treatment. Psychopharm (Berl) 2008, 199:1-14.

28. Schweizer M, Henniger M, Sillaber I: Chronic mild stress (CMS) in mice: of anhedonia, 'anomalous anxiolysis' and activity. PLoS One 2009, 4:e4326.

29. Michelsen K, van den Hove D, Schmitz C, Segers O, Prickaerts J, Steinbusch $\mathrm{H}$ : Prenatal stress and subsequent exposure to chronic mild stress influence dendritic spine density and morphology in the rat medial prefrontal cortex. BMC Neurosci 2007, 8:107.

30. Macrì S, Pasquali P, Bonsignore L, Pieretti S, Cirulli F, Chiarotti F, Laviola G: Moderate neonatal stress decreases within-group variation in behavioral, immune and HPA responses in adult mice. PLoS One 2007, 2:e1015.

31. Wood GE, Norris EH, Waters E, Stoldt JT, McEwen BS: Chronic immobilization stress alters aspects of emotionality and associative learning in the rat. Behav Neurosci 2008, 122:282-292.

32. Weiss J: Does decreased sucrose intake indicate loss of preference in CMS model? Psychopharm (Berl) 1997, 134:368-377.

33. Cabib S: What is mild in mild stress? Psychopharm (Berl) 1997, 134:344-346.

34. Harris R, Zhou J, Youngblood B, Smagin G, Ryan D: Failure to change exploration or saccharin preference in rats exposed to chronic mild stress. Physiol Behav 1997, 63:91-100.

35. Forbes N, Stewart C, Matthews K, Reid IC: Chronic mild stress and sucrose consumption: validity as a model of depression. Physiol Behav 1996, 60:1481-1484.

36. Nielsen C, Arnt J, Sanchez C: Intracranial self-stimulation and sucrose intake differ as hedonic measures following chronic mild stress: interstrain and interindividual differences. Behav Brain Res 2000, 107:21-33.

37. Matthews K, Forbes N, Reid I: Sucrose consumption as an hedonic measure following chronic unpredictable mild stress. Physiol Behav 1995, 57:241-248.

38. Strekalova T, Steinbusch H: Measuring behavior with chronic stress depression model in mice. Prog Neuropsychopharm Biol Psychiatry 2010, 34:348-361.

39. Strekalova T, Steinbusch H: Factors of reproducibility of stress-induced anhedonia in chronic stress depression models in mice. In Mood and Anxiety related phenotypes in mice: characterization using behavioral tests. Edited by: Gould T. Totowa, NJ, Humana Press; 2009:153-176.

40. Nestler E, Gould E, Manji H, Buncan M, Duman R, Greshenfeld H, Hen R, Kester S, Ledehendleer I, Meaney M, Robbins T, Winsky L, Zalcman S: Preclinical models: Status of basic research in depression. Biol Psychiatry 2002, 52:503-528.

41. Ducottet C, Aubert A, Belzung C: Susceptibility to subchronic unpredictable stress is related to individual reactivity to threat stimuli in mice. Behav Brain Res 2004, 155:291-296.

42. Strekalova T: The characteristics of the defensive behavior of rats in accordance with their resistance to emotional stress. Zh Vyssh Nerv Deiat Im I P Pavlova 1995, 45:420-422.

43. Ivannikova NO, Koplik EV, Popova EN, Sudakov KV: Emotional stress in the development of experimental hemorrhagic stroke in rats with different levels of stress resistance. Neurosci Behav Physiol 2011, 41:35-41.

44. Strekalova T, Spanagel R, Bartsch D, Henn F, Gass P: Stressed-induced anhedonia in mice is associated with deficits in forced swimming and exploration. Neuropsychopharm 2004, 11:2007-2017.

45. Strekalova T, Gorenkova N, Schunk E, Dolgov O, Bartsch D: Selective effects of citalopram in the mouse model of stress-induced anhedonia with control effects for chronic stress. Behav Pharm 2006, 17:271-287.

46. Strekalova T, Cespuglio R, Koval'zon V: Depressive-like state and sleep in laboratory mice. Zh Vyssh Nerv Deiat Im IP Pavlova 2008, 58:728-737.

47. Strekalova T: Optimization of the chronic stress depression model in $\mathrm{C} 57$ BL/6 mice: evidences for improved validity. In Behavioral models in stress research. Volume I. Edited by: Kalueff A, LaPorte J. New York, Nova Science Publishers Inc:; 2008:111-157. 
48. Strekalova T, Cespuglio R, Kovalson V: Sleep structure during chronic stress and anhedonia in the mouse model of depression. Behavioral models in stress research. Volume II NY, USA, Nova Science Publishers; 2009, 113-129.

49. Strekalova T, van Miegem V, Redkozubova O, Dolgov O, Larde G, Beznosko B, Vankin G, Bachurin S: Sucrose test method: Facts, artifacts and application in anhedonia models with young and old C57BL/6 mice. Int J Nuropsychopharm 2008, 11(Suppl 1):128.

50. Cao JL, Covington HE, Friedman AK, Wilkinson MB, Walsh JJ, Cooper DC, Nestler EJ, Han MH: Mesolimbic dopamine neurons in the brain reward circuit mediate susceptibility to social defeat and antidepressant action. J Neurosci 2010, 48:16453-16458.

51. Covington HE, obo MK, Maze I, Vialou V, Hyman JM, Zaman S, LaPlant Q, Mouzon E, Ghose S, Tamminga CA, Neve RL, Deisseroth K, Nestler EJ: Antidepressant effect of optogenetic stimulation of the medial prefrontal cortex. J Neurosci 2010, 48:16082-16090.

52. Berton $\mathrm{O}$, Covington HE, Ebner $\mathrm{K}$, Tsankova NM, Carle TL, Ulery $\mathrm{P}$, Bhonsle A, Barrot M, Krishnan V, Singewald GM, Singewald N, Birnbaum S, Neve RL, Nestler EJ: Induction of deltaFosB in the periaqueductal gray by stress promotes active coping responses. Neuron 2007, 55:289-300.

53. Vialou V, Robison AJ, Laplant QC, Covington HE, Dietz DM, Ohnishi YN, Mouzon E, Rush AJ, Watts EL, Wallace DL, Iñiguez SD, Ohnishi YH, Steiner MA, Warren BL, Krishnan V, Bolaños CA, Neve RL, Ghose S, Berton O, Tamminga CA, Nestler EJ: DeltaFosB in brain reward circuits mediates resilience to stress and antidepressant responses. Nat Neurosci 2010, 13:745-752.

54. Bisgaard CF, Jayatissa MN, Enghild JJ, Sanchéz C, Artemychyn R, Wiborg O: Proteomic investigation of the ventral rat hippocampus links DRP-2 to escitalopram treatment resistance and SNAP to stress resilience in the chronic mild stress model of depression. J Mol Neurosci 2007 32:132-144.

55. Holm MM, Nieto-Gonzalez JL, Vardya I, Henningsen K, Jayatissa MN, Wiborg O, Jensen K: Hippocampal GABAergic dysfunction in a rat chronic mild stress model of depression. Hippocampus 2010.

56. Henningsen K, Andreasen JT, Bouzinova EV, Jayatissa MN, Jensen MS, Redrobe JP, Wiborg O: Cognitive deficits in the rat chronic mild stress model for depression: relation to anhedonic-like responses. Behav Brain Res 2009, 198:136-141.

57. Schmidt MV, Trümbach D, Weber P, Wagner K, Scharf SH, Liebl C, Datson N, Namendorf C, Gerlach T, Kühne C, Uhr M, Deussing JM, Wurst W, Binder EB, Holsboer F, Müller MB: Individual stress vulnerability is predicted by short-term memory and AMPA receptor subunit ratio in the hippocampus. J Neurosci 2010, 50:16949-16958.

58. Lagace DC, Donovan MH, DeCarolis NA, Farnbauch LA, Malhotra S, Berton O, Nestler EJ, Krishnan V, Eisch AJ: Adult hippocampal neurogenesis is functionally important for stress-induced social avoidance. Proc Natl Acad Sci USA 2010, 107:4436-4441.

59. Piazza $P V$, Maccari $S$, Deminière $J M$, Le Moal M, Mormède $P$, Simon H: Corticosterone levels determine individual vulnerability to amphetamine self-administration. Proc Natl Acad Sci USA 1991, 88:2088-2092.

60. Ducottet $C$, Belzung C: Correlations between behaviours in the elevated plus-maze and sensitivity to unpredictable subchronic mild stress: evidence from inbred strains of mice. Behav Brain Res 2005, 156:153-162.

61. Le Pen G, Gaudet L, Mortas P, Mory R, Moreau J: Deficits in reward sensitivity in a neurodevelopmental rat model of schizophrenia. Psychopharm (Berl) 2002, 161:434-441.

62. Bolivar V, Walters S, Phoenix J: Assessing autism-like behavior in mice: variations in social interactions among inbred strains. Behav Brain Res 2007, 176:2126.

63. Jakovcevski M, Schachner M, Morellini F: Individual variability in the stress response of $\mathrm{C} 57 \mathrm{BL} / 6 \mathrm{~J}$ male mice correlates with trait anxiety. Genes Brain Behav 2008, 2:35-43.

64. Ryan BC, Vandenbergh JG: Intrauterine position effects. Neurosci Biobehav Rev 2002, 26:665-678

65. Tsankova N, Berton O, Renthal W, Kumar A, Neve R, Nestler E: Sustained hippocampal chromatin regulation in a mouse model of depression and antidepressant action. Nature Neurosci 2006, 4:519-525.

66. Mill J, Petronis A: Molecular studies of major depressive disorder: the epigenetic perspective. Mol Psychiatry 2007, 12:799-814.

67. Rando O, Verstrepen K: Time scales of genetic and epigenetic inheritance. Cell 2007, 128:655-658
68. Alter M, Rubin D, Ramsey K, Halpern R, Stephan D, Abbott L: Variation in the large-scale organization of gene expression levels in the hippocampus relates to stable epigenetic variability in behavior. PLoS ONE 2008, 3:e3344

69. Prows D, Shertzer H, Daly M, Sidman C, Leikauf G: Genetic analysis of ozone-induced acute lung injury in sensitive and resistant strains of mice. Nature Gen 1997, 17:471-474.

70. Ponimaskin E, Dityateva G, Ruonala M, Fukata M, Fukata Y, Kobe F, Dityatev A: Fibroblast growth factor-regulated palmitoylation of the neural cell adhesion molecule determines neuronal morphogenesis. J Neurosci 2008, 28:8897-8907.

71. Strekalova T, Wotjak C, Schachner M: Intrahippocampal administration of an antibody against the HNK-1 carbohydrate impairs memory consolidation in an inhibitory learning task in mice. Mol Cell Neurosci 2001, 17:1102-1113.

72. Julie Vignisse, Harry WMSteinbusch, Alexei Bolkunov, Joao Nunes, Ana Isabel Santos, Christian Grandfils, Sergei Bachurin, Tatyana Strekalova: Dimebon enhances hippocampus-dependent learning in both appetitive and inhibitory memory tasks in mice. Progr Neuro-Psychopharm Biol Psych 2011, 35:510-522.

73. Artola A, von Frijtag JC, Fermont PC, Gispen WH, Schrama LH, Kamal A, Spruijt BM: Long-lasting modulation of the induction of LTD and LTP in rat hippocampal CA1 by behavioural stress and environmental enrichment. Eur J Neurosci 2006, 261-272.

74. Popoli M, Gennarelli M, Racagni G: Modulation of synaptic plasticity by stress and antidepressants. Bipolar Disord 2002, 4:166182.

75. Lesch KP: When the Serotonin Transporter Gene Meets Adversity: The Contribution of Animal Models to Understanding Epigenetic Mechanisms in Affective Disorders and Resilience. Curr Top Behav Neurosci 2011.

76. Dantzer R, O'Connor JC, Lawson MA, Kelley KW: Inflammation-associated depression: From serotonin to kynurenine. Psychoneuroendocrinol 2010, 36:426-436.

77. Deacon R: Burrowing in rodents: a sensitive method for detecting behavioral dysfunction. Nature Prot 2006, 1:118-121.

78. Freeman M, Freeman S, McElroy S: The comorbidity of bipolar and anxiety disorders: prevalence, psychobiology, and treatment issues. J Affect Disord 2002, 68:1-23.

79. Nutt D, Ballenger J, Sheehan D, Wittchen $\mathrm{H}$ : Generalized anxiety disorder: comorbidity, comparative biology and treatment. Int J Neuropsychopharmacol 2002, 5:315-325.

80. Rao U, Chen LA, Bidesi AS: Hippocampal changes associated with earlylife adversity and vulnerability to depression. Biol Psychiatry 2010, 67:357-364.

81. Milne A, MacQueen GM, Yucel K: Hippocampal metabolic abnormalities at first onset and with recurrent episodes of a major depressive disorder: a proton magnetic resonance spectroscopy study. Neuroimage 2009, 47:36-41.

82. Campbell SJ, Deacon RM, Jiang Y, Ferrari C, Pitossi FJ, Anthony DC: Overexpression of IL-1beta by adenoviral-mediated gene transfer in the rat brain causes a prolonged hepatic chemokine response, axonal injury and the suppression of spontaneous behaviour. Neurobiol Dis 2007, 2:151-163.

83. Chung ES, Chung YC, Bok E, Baik HH, Park ES, Park JY, Yoon SH, Jin BK: Fluoxetine prevents LPS-induced degeneration of nigral dopaminergic neurons by inhibiting microglia-mediated oxidative stress. Brain Res 2010, 1363:143-150.

84. Maes M: Depression is an inflammatory disease, but cell-mediated immune activation is the key component of depression. Prog Neuropsychopharmacol Biol Psychiatry 2010, 35:664-675.

85. Tonissaar $M$, Herm L, Rinken A, Harro J: Individual differences in sucrose intake and preference in the rat: circadian variation and association with dopamine D2 receptor function in striatum and nucleus accumbens. Neurosci Lett 2006, 403:119-124.

86. Bevins R, Besheer J: Novelty reward as a measure of anhedonia. Neurosci Biobehav Rev 2005, 29:707-714.

87. Slattery D, Markou A, Cryan J: Evaluation of reward processes in an animal model of depression. Psychopharm (Berl) 2007, 190:555-568.

88. Glendinning J, Gresack J, Spector A: A high-throughput screening procedure for identifying mice with aberrant taste and oromotor function. Chem Senses 2002, 27:461-474. 
89. Coudereau J, Stain F, Drion N, Sandouk P, Monier C, Debray M, Scherrmann JM, Bourre J, Frances $\mathrm{H}$ : Effect of social isolation on the metabolism of morphine and its passage through the blood-brain barrier and on consumption of sucrose solutions. Psychopharm (Berl) 1999, 144:198-204

90. O'Callaghan M, Croft A, Little H: Effects of intraperitoneal injections of saline on the alcohol and sucrose consumption of C57/BL10 mice. Psychopharm (Berl) 2002, 160:206-212.

91. Krimm R, Nejad M, Smith J, Miller I Jr, Beidler L: The effect of bilateral sectioning of the chorda tympani and the greater superficial petrosal nerves on the sweet taste in the rat. Physiol Behav 1987, 41:495-501.

92. Adriani W, Macri S, Pacifici R, Laviola G: Restricted daily access to water and voluntary nicotine oral consumption in mice: methodological issues and individual differences. Behav Brain Res 2002, 134:21-30.

93. Amico J, Vollmer R, Cai H, Miedlar J, Rinaman L: Enhanced initial and sustained intake of sucrose solution in mice with an oxytocin gene deletion. Am J Physiol Regul Integr Comp Physiol 2005, 289:R1798-806.

94. Heyman SE: How mice cope with stressful social situations. Cell 2007. 131:232-234

95. Vachova H: Chronic stress depression model in mice. Social characteristics in mice and their physiological correlates: two studies. Diploma work at the department of zoology, Charle's University in Prague 2004, 2-32.

96. Willner P, D'Aquila P, Coventry T, Brain P: Loss of social status: preliminary evaluation of a novel animal model of depression. J Psychopharmacol 1995, 9:207-213.

97. D'Amato F, Rizzi R, Moles A: A model of social stress in non-submissive mice: effects on sociosexual behaviour. Physiol Behav 2001, 73:421-426.

98. Von Frijtag J, Reijmers L, Van der Harst J, Leus I, Van den Bos R, Spruijt B: Defeat followed by individual housing results in long-term impaired reward- and cognition-related behaviours in rats. Behav Brain Res 2000, 117:137146.

99. Malatynska E, Knapp R: Dominant-submissive behavior as models of mania and depression. Neurosci Biobehav Rev 2005, 29:715-737.

100. Krishnan V, Nestler EJ: Linking molecules to mood: new insight into the biology of depression. Am J Psychiatry 2010, 167:1305-1320.

101. Krsiak M: Timid singly-housed mice: their value in prediction of psychotropic activity of drugs. Br J Pharmacol 1975, 55:141-150.

102. Krsiak M, Podhorna J, Miczek K: Aggressive and social behavior after alprazolam withdrawal: experimental therapy with Ro 19-8022. Neurosci Biobehav Rev 1998, 23:155-161.

103. Hata T, Itoh E, Nishikawa H: Behavioral characteristics of SART-stressed mice in the forced swim test and drug action. Pharmacol Biochem Behav 1995, 51:849-853.

104. Hata T, Nishikawa $H$, Itoh E, Funakami Y: Anxiety-like behavior in elevated plus-maze in repeatedly cold stressed mice. Jpn J Pharmacol 2001, 85:189-196.

105. Cancela L, Bregonzio C, Molina V: Anxiolytic-like effect induced by chronic stress is reversed by naloxone pretreatment. Brain Res Bull 1995, 36:209-213.

106. D'Aquila P, Brain P, Willner P: Effects of chronic mild stress on performance in behavioural tests relevant to anxiety and depression. Physiol Behav 1994, 56:861-867.

107. Rossler A, Joubert C, Chapouthier G: Chronic mild stress alleviates anxious behaviour in female mice in two situations. Behav Processes 2000, 49:163-165.

108. Strekalova T, Spanagel R, Dolgov O, Bartsch D: Stress-induced hyperlocomotion as a confounding factor in anxiety and depression models in mice. Behav Pharm 2005, 16:171-180.

109. Cao L, Hudson C, Moynihan J: Chronic foot shock induces hyperactive behaviors and accompanying pro- and anti-inflammatory responses in mice. J Neuroimmunol 2007, 186:63-74.

110. Wakizono T, Sawamura T, Shimizu K, Nibuya M, Suzuki G, Toda H, Hirano J, Kikuchi A, Takahashi Y, Nomura S: Stress vulnerabilities in an animal model of post-traumatic stress disorder. Physiol Behav 2007, 90:687-695.

111. Becker C, Zeau B, Rivat C, Blugeot A, Hamon M, Benoliel J: Repeated social defeat-induced depression-like behavioral and biological alterations in rats: involvement of cholecystokinin. Mol Psychiatry 2008, 13:1079-92.

112. Sanchez C: Acute stress enhances anxiolytic-like drug responses of mice tested in a black and white test box. Eur Neuropsychopharm 1997, 7:283-238
113. Heiderstadt K, McLaughlin R, Wright D, Walker S, Gomez-Sanchez C: The effect of chronic food and water restriction on open-field behavior and serum corticosterone levels in rats. Lab Anim 2000, 34:20-28.

114. Burne T, O'Loan J, McGrath J, Eyles D: Hyperlocomotion associated with transient prenatal vitamin $\mathrm{D}$ deficiency is ameliorated by acute restraint. Behav Brain Res 2006, 174:119-124.

115. Negroni J, Venault P, Pardon M, Perez-Diaz F, Chapouthier G, CohenSalmon C: Chronic ultra-mild stress improves locomotor performance of B6D2F1 mice in a motor risk situation. Behav Brain Res 2004, 155:65-73.

116. Bertoglio L, Carobrez A: Behavioral profile of rats submitted to session 1session 2 in the elevated plus-maze during diurnal/nocturnal phases and under different illumination conditions. Behav Brain Res 2002, 132:135-113.

117. Igarashi $E$, Takeshita S: Effects of illumination and handling upon rat open field activity. Physiol Behav 1995, 57:699-703

118. Valentinuzzi V, Buxton O, Chang A, Scarbrough K, Ferrari E, Takahashi J, Turek F: Locomotor response to an open field during C57BL/6J active and inactive phases: differences dependent on conditions of illumination. Physiol Behav 2000, 69:269-275.

119. Murison $\mathrm{R}$, Hansen $\mathrm{A}$ : Reliability of the chronic mild stress paradigm: implications for research and animal welfare. Integr Physiol Behav SCi 2001, 36:266-274.

120. Pijlman F, Wolterink G, Van Ree J: Physical and emotional stress has differential effects on preference for saccharine and open field behaviour in rats. Behav Brain Res 2003, 139:131-138.

121. Ikemoto S, Panksepp J: The role of nucleus accumbens dopamine in motivated behavior: a unifying interpretation with special reference to reward-seeking. Brain Res Brain Res Rev 1999, 1:6-41.

122. Crawley J, Moody T: Anxiolytics block excessive grooming behavior induced by ACTH1-24 and bombesin. Brain Res Bull 1983, 10:399-401.

123. Skuse D, Albanese A, Stanhope R, Gilmour J, Voss L: New stress-related syndrome of growth failure and hyperphagia in children, associated with reversibility of growth-hormone insufficiency. Lancet 1996, 348:353-358.

124. Schoenecker B, Heller K, Freimanis T: Development of stereotypies and polydipsia in wild caught bank voles (Clethrionomys glareolus) and their laboratory-bred offspring. Is polydipsia a symptom of diabetes mellitus? Appl Anim Behav Sci 2000, 68:349-357.

125. Cole B, Koob G: Corticotropin-releasing factor and schedule-induced polydipsia. Pharmacol Biochem Behav 1994, 47:393-398.

126. Yirmiya R, Goshen I, Bajayo A, Kreisel T, Feldman S, Tam J, Trembovler V, Csernus V, Shohami E, Bab I: Depression induces bone loss through stimulation of the sympathetic nervous system. Proc Natl Acad Sci USA 2006, 45:16876-168781

127. Mendlewicz J: Sleep disturbances: core symptoms of major depressive disorder rather than associated or comorbid disorders. World J Biol Psychiatry 2009, 10:269-275.

128. Wilkinson M, Xiao G, Kumar A, LaPlant Q, Renthal W, Sikder D, Kodadek T, Nestler E: Imipramine treatment and resiliency exhibit similar chromatin regulation in the mouse nucleus accumbens in depression models. $J$ Neurosci 2009, 29:7820-7832.

129. Perlis $R$, Moorjani $P$, Fagerness J, Purcell S, Trivedi M, Fava M, Rush A, Smoller J: Pharmacogenetic analysis of genes implicated in rodent models of antidepressant response: association of TREK 1 and treatment resistance in the STAR(*)D study. Neuropsychopharm 2008, 33:2810-2819.

130. Maina G, Albert U, Salvi V, Bogetto F: Weight gain during long-term treatment of obsessive-compulsive disorder: a prospective comparison between serotonin reuptake inhibitors. J Clin Psychiatry 2004, 65:1365-1371.

131. Hayward C, Wilson K, Lagle K, Kraemer H, Killen J, Taylor C: The developmental psychopathology of social anxiety in adolescents. Depress Anxiety 2008, 25:200-206.

132. Stahl S: Phenomenology of anxiety disorders: clinical heterogeneity and comorbidity. In Advances in the Neurobiology of Anxiety Disorders. Edited by: Westenberg H, Den Boer J, Murphy D. John Willey 1996:21-38.

doi:10.1186/1744-9081-7-9

Cite this article as: Strekalova et al:: Update in the methodology of the chronic stress paradigm: internal control matters. Behavioral and Brain Functions 2011 7:9. 